\title{
THE NOMINAL RIGIDITY \\ OF APARTMENT RENTS
}

\section{David Genesove}

\author{
Working Paper 7137 \\ http://www.nber.org/papers/w7137 \\ NATIONAL BUREAU OF ECONOMIC RESEARCH \\ 1050 Massachusetts Avenue \\ Cambridge, MA 02138 \\ May 1999
}

The views expressed herein are those of the authors and do not necessarily reflect the views of the National Bureau of Economic Research.

(C) 1999 by David Genesove. All rights reserved. Short sections of text, not to exceed two paragraphs, may be quoted without explicit permission provided that full credit, including $(\mathcal{C}$ notice, is given to the source. 
The Nominal Rigidity of Apartment Rents

David Genesove

NBER Working Paper No. 7137

May 1999

JEL No. L16, E30

\begin{abstract}
This paper contributes to the empirical literature on price stickiness by documenting a high rate of nominal rigidity among apartment rents in the U.S. between 1974-1981. 29 percent of units had no change in nominal rent from year to year. Nominal rigidity was much higher among units whose tenants continued from the previous year, than those in which the tenant turned over. This suggests that the previous year's nominal price was used as a focal point in bargaining. Most of the nominal rigidity among units that turned over can be ascribed to grid pricing, while most of the incidence among the units that did not turn over can not be thus explained, and probably reflects downward rigidity instead. Units in single-unit and small buildings were much more likely to display nominal rigidity.
\end{abstract}

David Genesove

Department of Economics

Hebrew University of Jerusalem

Mount Scopus, Jerusalem 91905

ISRAEL and NBER

genesove@mscc.huji.ac.il 
Much of the debate in macroeconomics turns on the stickiness of nominal prices, to which one part of the literature ascribes monetary non-neutrality and the propagation of demand-side business fluctuations. Although whether micro level stickiness must lead to substantial nominal rigidity at the aggregate level remains an open question, certainly a prerequisite of the 'New-Keynesian' approach is that such rigidity exists at the micro level. ${ }^{1}$

I document a high degree of nominal rigidity in apartment rents. Over the period of 1974-1981, twenty nine percent of the apartments in my sample from the Annual Housing Survey (AHS) National panel had no change in nominal rent from one year to the next. About half of that fraction can be attributed to grid pricing; the rest I interpret as downward rigidity .

The incidence varies with observable determinants in clear, and intuitive, patterns. Nominal rigidity is higher in years and in cities that have a low median nominal growth rate. Across years the incidence is nearly perfectly ranked with the median growth rate. Units that turn over have a lower, though still substantial, incidence than those units in which the tenant stays an additional year; however, most, and perhaps nearly all, of the

\footnotetext{
${ }^{1}$ Generally, the relevant theoretical literature adopts a menu cost approach. Caplin and Spulber (1987) show that when firms adopt an ss type policy in price adjustment (which Sheshinski and Weiss had shown to be optimal), and inflationary shocks are all positive, that money is neutral. Neutrality fails when monetary shocks can be both positive and negative, as in Caplin and Leahy (1991).
} 
incidence for turnover units can be ascribed to grid pricing. The incidence of nominal rigidity is also higher for units located in smaller buildings.

Others have shown evidence of nominal price rigidity before, although only for goods that represent a tiny share of consumer expenditure. Thus Cechetti (1986) showed that even in the high inflation decade of the 1970s, the newsstand price of magazines remained unchanged for three and a quarter years, on average. Kashyap (1995) followed the prices of several items, such as chamois shirts, and fishing rods in the L. L. Bean, Orvis and R.E.I. semiannual catalogues, and found that nominal prices typically lasted for more than a year. Lach and Tsiddon, working with Israeli data on 26 products - principally wine, fish and meat -, showed that from 1978 through mid 1979, when the average monthly inflation rate was 4 percent, the average duration of a nominal price quotation was nonetheless 2.5-3 months. Evidence of a different sort is provided by Levy, Bergen, Dutta and Venable (1997) who in a recent article report for a small sample of supermarket chains that only 70-80 percent of prices are changed in response to wholesale price changes.

For Ball and Mankiw (1994), that the individual goods examined are small budget items is to be expected. "For this theory, the most important prices are for those goods bought with money, since the price of goods bought with credit do not directly affect the 
demand for money. Goods bought with money tend to be small retail items, such as newspapers and haircuts." (p. 131)

One suspects, nonetheless, that the authors would be glad to find nominal rigidity in a good that is not a "small retail item". Indeed, housing is perhaps the one large consumer item that is not paid with credit. For the renters of the units in my sample, housing expenditures constitutes 20 to 30 percent of their yearly income. Aside from the importance of this sector to the economy, it is especially interesting to find nominal rigidity in a good whose asset prices are known to be quite volatile.

The manner of price determination in the rental housing market also distinguishes this good from those examined in prior research. Unlike the market for magazines or L. L. Bean chamois shirts, where a single seller of a homogenous good sets a price common to many consumers, who may purchase at will, the market for rental housing consists of heterogenous goods for which negotiation typically attends each transaction. Few apartments are rented in the anonymous manner of "small retail goods". Price may be tailored by the landlord to the particular tenant, or it may be determined in bargaining between the two. Even when a landlord follows a fixed rent policy, the opportunity to deviate from that policy is costlessly available, for a new contract must be produced for each new tenant and at each lease renewal regardless of price. To use the metaphor of "menu costs", a new menu necessarily attends every transaction. Given this, the observed nominal rigidity must be the 
result of some phenomenon other than menu costs, which is the leading explanation for nominal rigidity in the earlier studies. ${ }^{2}$ Indeed, the distribution of nominal rent changes suggests a form of nominal rigidity more like that of downward price rigidity than what would be produced by menu costs. Although small price increases and decreases are relatively rare, as a menu cost argument would predict (for a single product firm), it is the scarcity of large negative changes that it is most striking. Because the rarity of small absolute changes can also be explained by grid pricing, and, as argued above, the nature of transactions make the menu cost argument untenable, I reject the menu cost explanation

Of course, to speak of a certain type of price changes as "missing" one must have a notion of what the growth of rents would look like in the absence of nominal rigidity. In very high inflationary periods, as in Israel during the period examined by Lach and Tsiddon, or the Argentina of Tomassi, any change in the real frictionless real price would typically be swamped by the effects of inflation. The primary goal of a price setter in these circumstances is to keep up with inflation, and so the natural

\footnotetext{
${ }^{2}$ Kashyap notes that a price change requires that the relevant catalogue page be recomposed, with the attendant costs. Levy et al is quite explicitly about menu costs, which they measure directly. The exception is Cechetti - every magazine issue has a new cover and so could have a new price costlessly! Cechetti ascribes the nominal rigidity to coordination problems in collusion of the sort that Sweezy's (1939) kinked demand curve is meant to capture.
} 
benchmark to which to compare nominal price changes is the inflation rate itself. In our case, inflation was moderately high while real rent was declining. Over the 1974-1981 period, the consumer price index rose 84 percent while the median nominal rent increased by 44.5 percent - or $9.2 \%$ and $5.4 \%$ annually. Thus some benchmark other than simply the inflation rate is needed.

In constructing the counterfactual rent growth distribution, I assume that the observed distribution is the outcome of censoring of an underlying unobserved distribution in which some negative and some small positive proportional increases in rent are replaced by a zero increase in the observed data. Following Card and Hyslop's (1996) work on wage rigidity, I assume, additionally, that (a) there is no censoring above the median, and (b) the underlying distribution is symmetric. Together, this allows me to construct the counterfactual distribution from that part of the observed distribution above the median.

In the following section, I document how nominal rigidity depends upon the median growth rate in nominal rent, turnover status and building size. In section 2, I show that these results reflect nominal rigidity across different contracts and do not result from within lease interviewing. Section 3 discusses grid pricing, which, in this market, is the tendency to set prices that are multiples of certain dollar amounts. Sections 4 and 5 attempt in various ways to determine the contribution of grid pricing to nominal rigidity. Section 4 constructs a counterfactual 
distribution function which is used, first, to provide an upper bound for, and then to explicitly calculate, the contribution of grid pricing. In section 5 I estimate a probit regression, thus providing a multivariate analysis of nominal rigidity. The regressors include a set of dummy variables for the grid point of the previous year's rent. Section 6 considers whether adjustments along other margins substitute for nominal price adjustments. Section 7 concludes.

\section{The Incidence Level, Turnover and Building Size}

\section{IA. Some Basic Facts}

The Annual Housing Survey, National Sample (1974-1981) is a panel of housing units, based on the 1970 Census. $^{3}$ It is an unbalanced sample, principally because samples of newly constructed units are added each year, other units are demolished, and a few interviews are not completed. I restrict the sample to units in SMSAs (Standard Metropolitan Statistical Areas) with no rent control restrictions over the 1974-1981 period." (The AHS gives no

${ }^{3}$ The 1973 survey cannot be matched to the later ones. Since 1981 the survey has been conducted biannually, so that AHS now stands for the American Housing Survey. A new sample, based on the 1980 Census, was drawn in 1985, and a 1990 Census based sample drawn in 1995.

${ }^{4}$ SMSAs with rent control are identified primarily by National Multihousing Council (1981 and 1982), as well as Baar (1983), Downs(1988), Gilderbloom and Applebaum (1988), Gilderbloom and Friends (1981), Capek and Gilderbloom (1992), Block and Olsen (1981), Niebanck (1985), Rydell et al (1981), and 
location information below the state level for units outside SMSAs.) Those cities are listed in Table 1. Of the three largest American cities, New York City is absent as it has had rent control of some sort or another over the post-war years, and Los Angeles is absent since rent control was imposed in 1979, leaving Chicago the largest city represented. Only units for which rent is paid monthly and is recorded (rent above $\$ 1999$ per month is top coded, and I drop such units), and which are neither in public housing nor are occupied by tenants whose rent is partly subsidized by the government are included; these conditions are required to hold for the year and the previous year. There are 11,418 observations, each constituting a housing unit and two adjacent years of completed interviews.

I measure a unit's nominal growth rate by $\mathrm{dr} \equiv \ln \mathrm{R}_{\mathrm{t}}-\ln \mathrm{R}_{\mathrm{t}-1}$, where $R_{t}$ is the nominal rent in year $t$. It is obtained from the answer to the question "What is the monthly rent?" in the year $t$ interview. Figure 1 displays the empirical cumulative distribution function of dr, by year. Almost all of the dispersion reflects differences in growth rates within the SMSAS. In 1981, for example, the overall variance of dr was .08, while the variance of the mean dr across SMSAs was a mere .007.

The fraction of units with no nominal rent change is measured by the length of the vertical line at zero. Clearly, there is a

The Report to Congress on Rent Control (1991). 
large degree of nominal rigidity in all years. There is no evidence of real rigidity, that is, a growth rate equal to the inflation rate, as zero is the only "mass point" in any of the years.

Some summary statistics of the distributions are presented in Table 2, also by year. The incidence of nominal rigidity varies between 23 and 34 percent, with an average of 29 percent across all years.

Table 2 also shows that the incidence of nominal rigidity is positively correlated with the inflation rate. This is to be expected: a fixed nominal price is harder to sustain in an inflationary environment. The incidence is more closely associated with the median growth rate of nominal rent, with which it is nearly perfectly ranked. (I choose the median as the indicator of location, for it is natural to view zero nominal changes as replacing what would otherwise by decreases or small increases in the nominal rent, and the median, unlike the mean, is unaffected by such censoring.)

The incidence of positive nominal growth is also nearly ranked with the median. But, interestingly, the incidence of a nominal decrease is not. This is perhaps due to the rarity of this event, which subjects it to a greater sampling variance. But it also suggests that much of the negative growth rates represents 
measurement errors. ${ }^{5}$ Note that classical measurement error in responses to questions about the rent level would lead to a downward bias is measuring nominal rigidity. The table also shows that the dispersion, measured as the difference between the median and the 75th percentile, is relatively constant across years. I use this measure rather than the standard deviation, because the former is unaffected by censoring below the median.

The relationship between the incidence of nominal rigidity and the overall growth rate can be explored at the SMSA level as well. Figure 2 plots the two against each other, by year. When the incidence is sufficiently high, the complication of a zero median arises, although this occurs for small SMSAS sample sizes only. Table 3 summarizes these graphs by the regression of the nominal incidence on the median growth rate. This can either be regarded as merely a representation of the data, or, under the censoring interpretation, as casual. In any case, the first column shows that a one percent increase in the median growth rate decreases the incidence of nominal rigidity by 1.4 percent - and predicts (out of sample) that a median growth rate of 17 percent will exhibit no nominal rigidity at all. Interestingly, Card and Hyslop also find a one percent increase in inflation decreases the incidence of nominal wage rigidity by 1.4 percent. Conditioning on SMSA or

${ }^{5}$ Akerlof, Dickens and Perry (1996)have similarly argued that most observed individual negative wage growth (within jobs) is measurement error. 
year, as in Columns (2) and (3), reduces the effect of median growth rate, but the coefficient remains significant, both here and in the remaining columns, which restrict the sample to non-zero median rents.

\section{IB Turnover Status}

Nominal rigidity also varies with turnover status. A unit is identified as having turned over between the two interviews if the interviewer checked "Yes" to the statement "Household head moved here during the last 12 months", after having posed the question: "When did ... (head) move into this house (apartment)?", which is answered in the year and month. ${ }^{6}$ Table 4 presents some statistics on turnover status. The first row shows that about one-third of all units turn over every year. The remaining rows pertain to a subsample in which the turnover status for the previous three years is ascertainable. They show that the turnover hazard is decreasing: half of all units change hands after a year; of those in which the tenant remains, one-third turn over in the year after, with declining fractions for subsequent years.

Table 5, columns (1) through (3), displays the proportions of units that experienced a nominal decline, nominal increase and no

${ }^{6} \mathrm{Tn}$ the data for the 1979, 1980 and 1981 surveys, the Bureau computes a variable, HHOLD, which keeps a count of the number of different households since the 1974 survey. Increases in HHOLD correspond to the turnover classification described in the text 96 percent of the time. 
nominal change, by tenure status and year. Overall, some 36 percent of units in which the tenant remains the same experience no change in nominal rent, against 14 percent of units in which there is a new tenant. The incidence of nominal rent rigidity among continuing tenants is much greater than the fifteen percent that Card and Hyslop report for nominal wage rigidity among their sample of non-job changers for 1979-1992 from matched CPS data, or the seven percent that Kahn reports for her similar, but earlier 19791988 sample from the PSID. In columns (4) - (6) of the same table, the sample is restricted to units that obtained a new tenant in the previous year. The general pattern is always the same.

Tables 2 and 4 present two different, but related aspects of the behavior of rental growth rates. For a complete picture, one requires the empirical cumulative distribution function, which Figure 3 displays, by year and by tenure status, for those units that had turned over in the previous year. The more lightly shaded curve represents the distribution of turnover units. There are five noticeable aspects of this figure: (i) There is a large mass at zero nominal change, larger for the non-turnover units but still substantial for the turnover units. (ii) Above zero, the two distributions differ in location only. The median growth rate for turnover units is about four percent greater than for other units. Notwithstanding the greater nominal rigidity of the latter units, the mean growth rate differential is also about four percent. (ii) Near and above zero, the distributions flatten out, 
indicating few small positive changes. (iv) The lower tail of the distributions are indistinguishable, except for the first two pairs of years. (v) The non-turnover distribution is more stable over time: variations in the location differential of the two distributions is due to shifts in the turnover distribution.

My interpretation of the differential in median growth rates according to tenure is that when tenants remain a second year in the unit, there is ex-post surplus in the tenant-landlord relationship, so that the negotiated price differs from the market price. Furthermore, last year's nominal price represents a focal point in bargaining. As an explanation for overall nominal rigidity this explanation is perhaps incomplete, as it appears not to explain nominal rigidity among turnover units. But one would expect bargaining there, too, (once landlord and potential tenant meet there may be some ex-post surplus because of saved search costs) and it is not unlikely that a new tenant will know last year's price (as when the new tenant is acquaintated with the old). Furthermore, we will see that most, and perhaps nearly all, of the nominal rigidity among such units can be explained by grid pricing. Admittedly, an efficient turnover view of the housing market undercuts the macroeconomic significance of a finding of nominal rigidity. For under this view, using last year's rent for this year has only distributive, and no allocative effect. Nevertheless, one suspects that if individuals allow nominal concerns to determine distributional outcomes, which are as 
important to them as allocative ones are, that nominal considerations will affect allocative outcomes as well.

An alternative explanation is that low rents are associated with continuing tenants because existing tenants have the first right of refusal on the offer. Thus, according to this view, rents determine turnover status. Discriminating between these two explanations is the concern of another paper, but I will briefly indicate why I think the alternative explanation is less convincing. Consider the simplest story along these lines that one can tell about the first renewal discount: the landlord sets a price equal to the area wide rental growth rate, plus some random component. We can think of this componenet as the landlord's mistake; an equally good interpretation is that it reflects differing discount rates or search costs among landlords. Tenants lucky enough to have a landlord who sets a low price are more likely to remain in the apartment.

The story falters on the dynamic effects of the observed tenure discount. Not only is the rental growth rate 4 percent less when the tenant continues on into a second year, it is another 5 percent less when he continues on into a third year - so that at his second renewal date, a continuing tenant pays nine percent less than the 'market' level. Label the random component of the rent level set by the landlord $y$ and the tenant's disutility of moving x. Assume that $y$ is i.i.d., with distribution $G$, and that the equilibrium distribution of $x$ for (potential) first renewal 
tenants, $F_{1}$, either stochastically dominates or is dominated by the distribution of disutility from moving for (potential) second renewal tenants, $F_{2}$. Thus either $F_{1}(x) \leq F_{2}(x)$ for all $x$, or $F_{1}(x)$ $\geq F_{2}(x)$ for all $x$. A tenant will stay if and only if $y<x$. As Table 4 showed, half of all tenants remain a second year, and two thirds of those remain for a third year. Thus by the alternative hypothesis, $\int G(x) d F_{1}(x)-\int G(x) d F_{2}(x)=.5-.67<0$, so, by my assumption, $F_{2}$ stochastically dominates $F_{1}$. The expected rent for a type a tenant who stays after $i$ years is $E_{G}[x \mid x \leq a] d F_{i}(a)$, so that the differential rent between second year tenants and third year tenants is $E_{G}[y \mid y \leq x] d\left\{F_{1}(x)-F_{2}(x)\right\}$. By the assumption on stochastic dominance, this term must be negative. But the opposite is true for, as I said above, third year tenants pay 5 percent less than second year tenants.

\section{C. Building Size}

Finally, the degree of nominal rigidity also varies with the number of "living quarters, both occupied and vacant, ..., in [the] house (building)". Table 6 shows the incidence by building size. We see that units in smaller buildings have a greater incidence of nominal rigidity. It is natural to associate the number of living quarters in the building with the number of units owned by the landlord. A very natural explanation for this finding, then, is that small landlords are less "professional" than large ones, so 
that nominal rigidity is a manifestation of "irrationality". That grid pricing is also more prevalent in smaller buildings provides some support for this interpretation. ${ }^{7}$

Alternatively, one might argue that large landlords simply do not bargain with their tenants, thus eliminating the old nominal price as a possible outcome due to its role as a focal point. Tenants do not bargain with large landlords for the same reasons that consumers do not bargain with large department stores, although they might with a small retailer, or in the shuk. (These reasons might include a strategic commitment to a price, or a principal's regulation of its agents, i.e., salespeople.) If this explanation for the differential behavior of large and small landlords is the correct one, the finding has obvious implications for the changing sensitivity of economies to nominal shocks as they develop and large retailing units become more prevalent.

\section{Contractual vs. Non-Contractual Rigidity}

To what extent does the observed nominal rigidity reflect fixed prices within a contract? Clearly, none at all for turnover units; the two reported rents are, by definition, from different

${ }^{7}$ For example, among single detached homes, rents that are not multiples of 5 are quoted only 5 percent of the time, compared to 26 percent of the time among units in buildings of 50 or more units. The probit analysis in section 6 shows that the dependence of nominal rigidity on building size remains, even when grid pricing is controlled for. 
contracts. For non-turnover units, whether the quoted monthly rents originate from different contracts or not is not observable. Unfortunately, the AHS reports neither the term of the lease - or even if there is a lease - nor the date of the interview.

The Property Owners and Managers Survey (POMS), which was administered to the owners or managers of a sample of units drawn from the 1993 American Housing Survey sample, does report the term. The POMS sample differs from the sample I use from the AHS not only because of the difference in years, but also because, as the PoMS does not reveal the city, I cannot restrict the sample to the SMSAs of the principle sample. However, I do drop from the POMS sample all units not in MSAs, and units under rent control or receiving a government subsidy .

Table 7 shows the distribution of lease terms, by building size. Very few leases are for more than a year. ${ }^{8}$ A substantial fraction, about fifteen percent, of units have no lease at all. Of the remainder, about half of all leases are for a year, and half are for less a year. Units in larger buildings are much more likely to have a lease, and, conditional on having a lease, are

\footnotetext{
${ }^{8}$ Hubert's (1995) adverse selection model suggests one explanation for why there are so few leases longer than one year. In this model, the term of the lease is used as a screening device, since good tenants will be more willing to accept shorter term leases - or even "tenant at will" status -, at lower rents, than bad tenants.
} 
more likely to have a year-long lease. ${ }^{9}$

If one could be sure that the AHS interview dates were a year apart then, given the distribution of lease terms, one could conclude that the quoted rents were almost surely from different contracts. Table 8, however, shows that the AHS is conducted in the fall of the year over more than a one month period. It is thus conceivable that the interviews for a given unit were conducted less than one year apart, and so, even with a one year lease, within the same contractual period (although it is not conclusively so, because the Census Bureau might have surveyed the units in the same sequence in both years, and one suspects that most of the interviewing is concentrated at the beginning of each period). A difference of less than one year between the two interview dates would not alter the finding of nominal rigidity, only how much of it can be ascribed to fixed nominal contracts.

And yet the timing of interviews does not seem to be the reason for the nominal rigidity finding. First, note that the reported interview periods for the 1974 and 1975 surveys overlap in October only, whereas all the remaining pairs of years have a three or four month overlap. If a substantial part of the nominal rigidity were due to less than full year interview gaps, we would expect to see a much greater degree of nominal rigidity, twice or

${ }^{9}$ Since units in larger buildings are more likely to have the same lease covering both interviews, any bias resulting out of the timing of the interviews cannot explain why they also have a lower incidence of nominal rigidity. 
three times as much, in 1975-6 and subsequent years than in 1974-5. Yet 1974-5 growth rates look very much like the rest.

Second, our earlier result showing that nominal rigidity was decreasing in the SMSA median growth rate can be used to bound any bias. There is no reason to suppose that the incidence of two interview dates within the same lease period is at all dependant on the median growth rate. Thus the degree of nominal rigidity at the highest median growth rate is an upper bound to the contribution of within lease interviewing to observed nominal rigidity. A glance of Figure 3 shows that figure to be about 7 percent.

That upper bound is far too high, however. In columns (7) through (9) of Table 5 the sample is restricted to units in which the previous year's tenant originally moved in during the months of January through July. If leases are indeed yearly, or shorter, then interviews for these units in the Fall will capture different contracts. Yet these columns display no reduction in nominal rigidity. In fact, none of the results change with the restricted sample.

The fourth piece of evidence on this point comes from the micro level data that the Bureau of Labor Statistics collects in constructing the CPI rent index. The BLS uses a panel of housing units for this, returning every six months to record the apartment rent. I have 1988-1992 data. Over those years, the degree of nominal rigidity measured at eighteen month intervals is 37 
percent, ${ }^{10}$ which is higher than the $29 \%$ incidence that we document here.

Finally, one also observes nominal rigidity at two year intervals in the AHS. Ten percent of non-turnover units have the same nominal rent in year $t$ as in year $t-2$. This is more than the seven percent one expect were nominal rigidity in one year independent of nominal rigidity in the next. Since only 3 percent of leases are for more than a year, most of these occurrences must reflect rigidity across different contracts.

Taken together, all these arguments suggest very strongly that interview gaps of less than a year are not a serious concern, and that one may safely assume that the reported rents originate from different leases.

\section{Grid Pricing}

It is sometimes asserted that observed nominal rigidity is the outcome of the restriction to pricing on a grid: that if prices are rounded to the nearest multiple of ten, for example, then small underlying shocks that would otherwise lead to a change in prices of four dollars, say, will result in no nominal change. Since what consequences this would have for monetary neutrality appears to be an open question, it is important to determine the extent to which

\footnotetext{
${ }^{10}$ Unfortunately, those data do not record building size and the tenure status variable lumps together all duration longer than six months, making further analysis of the data along the lines of this paper impossible.
} 
grid pricing is responsible for the incidence of nominal rigidity. ${ }^{11}$ Grid pricing is clearly present. Columns (a) and (b) of Table 9 shows the distribution of the modulus terms in reported rents in 1975 and 1981, respectively. For example, in 1975, 7.0 percent of units had rents that were multiples of $\$ 100$, and 8.4 percent had rents that were multiples of $\$ 50$, but not $\$ 100$. I have ordered the grid points in what seems a natural hierarchy; for example, where there is a tendency to price at $\$ 10$ intervals, there is also a tendency to price at $\$ 25$ intervals, but not necessarily vice versa. Predictably, there is a shift in the distribution over time as nominal prices and rents increase. Whereas in 1975, 12.8 percent were not multiples of $\$ 5$, in 1981 only 8.2 percent were.

Columns (a) and (b) overstate the extent of grid pricing. For example, some fraction of units priced at \$10 intervals reflect a tendency to price at $\$ 5$ intervals, not $\$ 10$. Columns (c) and (d) adjust for that . ${ }^{12}$ We see that almost 65 percent of rents in 1975

${ }^{11}$ Unfortunately, I have been unable to find any published discussion of this issue. It seems to be a matter of oral debate only.

${ }^{12}$ Let $\mathrm{p}$ be the vector of data in column (a), and define the $\operatorname{matrix} A=\left\{\begin{array}{rrrrrr}1 & 1 / 2 & 1 / 4 & 1 / 12 & 1 / 20 & 1 / 100 \\ 0 & 1 / 2 & 1 / 4 & 1 / 12 & 1 / 20 & 1 / 100 \\ 0 & 0 & 2 / 4 & 2 / 12 & 2 / 20 & 2 / 100 \\ 0 & 0 & 0 & 8 / 12 & 8 / 20 & 8 / 100 \\ 0 & 0 & 0 & 0 & 8 / 20 & 8 / 100 \\ 0 & 0 & 0 & 0 & 0 & 80 / 100\end{array}\right\}$

Then column (c) is the solution to $p=A b$. To understand $A$, consider row 4 of $A$, which distributes prices on the $\$ 10$ grid among the three rounding rules that could yield such an observed modulus of $\$ 10$. These are the rule of rounding to the nearest $\$ 1$ (of which the $\$ 10$ grid provides 8 of its 100 points), a rule that 
were priced according to a \$5 grid, and that pricing on a grid coarser than $\$ 25$ was quite rare.

Grid pricing is associated with nominal rigidity. Table 10 shows the incidence of nominal rigidity by grid point. The incidence is increasing in the hierarchy: only 12 percent of units on a \$1 grid point \$1 in 1974 had zero nominal growth over 1975-4, compared to 39 percent of units on a $\$ 100$ grid point. This difference is, of course, understated, given the comment in the above paragraph.

Could grid pricing explain all of the price rigidity in this market? The answer must be no. Grid pricing is relevant only to small desired changes, and it is equally effective in turning both desired increases and decreases into zero nominal changes. The comparison between the empirical and the counterfactual distribution in the next section will make that argument clearer.

\section{Counterfactual Rent Growth Distributions}

In this section, I construct counterfactual rent growth distributions in order both to examine how rents would look without nominal rigidity, and to ascertain how much of the rigidity is due

rounds to the nearest $\$ 5$ (of which the $\$ 10$ grid provides 8 of its 20 points) and a rule that rounds to the nearest $\$ 10$ or $\$ 25$ (of which the $\$ 10$ grid provides 8 of 12 points - under the assumption that $\$ 25$ is ranked above $\$ 10$ in the hierarchy). 
to grid pricing.

As noted in the introduction, the counterfactual distribution is based on an assumption that the uncensored distribution is symmetric. ${ }^{13}$ Symmetry can be justified on two grounds, as Card and Hyslop point out. First, most parametric distributions that one might use are symmetric, such as the normal. Second, the distribution of changes are likely to be symmetric even when the distribution of the levels is not; if $R_{t}$ and $R_{t-1}$ have the same distribution up to a location parameter, than the distribution of dr will be symmetric.

Using symmetry and the assumption of no censoring above the median, I construct the counterfactual distribution $F_{c}$ as

$$
\begin{aligned}
\mathrm{F}_{\mathrm{C}}(\mathrm{x}) & =1-\mathrm{F}_{\mathrm{E}}(2 \operatorname{med}-\mathrm{x}), \mathrm{x}<\operatorname{med} \\
& =1-\mathrm{F}_{\mathrm{E}}(\mathrm{x}) \quad, \mathrm{x} \geq \operatorname{med}
\end{aligned}
$$

where $\mathrm{F}_{\mathrm{E}}$ is the empirical distribution and med $=\mathrm{F}_{\mathrm{e}}^{-1}(0)$.

The first use of $F_{C}$ is to allocate the incidence of nominal rigidity between units whose nominal rent would otherwise have increased, which is $X^{\mathrm{P}} \equiv \mathrm{F}_{\mathrm{E}}(0+)-\mathrm{F}_{\mathrm{C}}(0)$ of the population of units, and those whose rent would have decreased, which fraction is $X^{\mathbb{N}} \equiv F_{C}(0)-$

${ }^{13}$ Khan (1998) assumes, in contrast, that uncensored distributions from different years differ only in a location parameter. This allows her to uses the location-corrected distribution of a year with small nominal rigidity as a counterfactual. The method is less useful here, since nominal rigidity is high in all years and as I need a "continuous" counterfactual distribution to predict the extent of grid pricing. 
$\mathrm{F}_{\mathrm{E}}\left(0^{-}\right)$. Figures $3 \mathrm{a}$ and $3 \mathrm{~b}$ overlay $\mathrm{F}_{\mathrm{e}}$ (in bold) with $\mathrm{F}_{\mathrm{c}}$ for 1975 and 1981, respectively. $X^{\mathrm{P}}$ is the length of the vertical line at 0 above $F_{C}(0)$, while $X^{N}$ is the length of the line below $F_{C}(0)$. The results for all years are collected in Panel (a) of Table 11. Column (1) shows $F_{C}(0)$, Column (2) presents the total observed incidence, while Columns (3) and (4) shows $X^{\mathrm{P}}$ and $X^{\mathbb{N}}$, respectively. These two columns sum to column (2). The table shows that while some units with nominally rigid prices would otherwise have had increased rents, in most cases the rent would have declined. Overall, about two-thirds of the nominally rigid units would otherwise have decreased in rents.

How much of the nominal rigidity derives from grid pricing and how much from downward rigidity? Twice $X^{\mathrm{P}}$ provides an upper bound for the contribution under the following conditions: (a) a given absolute desired price change leads to no nominal change because of grid pricing with the same likelihood, regardless of the direction of change, (b) downward rigid prices replace desired price reductions only, and (c) the counterfactual distributions are unimodal. Given the figures just reported, this indicates that, overall, at most two-thirds of the observed incidence is due to grid pricing

A more precise estimate is possible, without assuming unimodality and using the counterfactual rent growth and the initial rent level distribution, as well as the distribution of modulus 
terms from columns (c) and (d) from table 9. Let $h(x ; y)$ denote the closest value on a y-dollar grid to $x$. Then the observed rent growth rate on a y-dollar grid, when the initial rent level is $R$ and the desired percentage growth rate is dr, is $g(R, d r ; y)=$ In $\left[\mathrm{h}\left(\mathrm{Re}^{\mathrm{dr}} ; \mathrm{y}\right)\right]-\ln \mathrm{R}$. Calculate $\mathrm{F}_{\mathrm{gpt}, \mathrm{y}}(\mathrm{x}) \equiv \operatorname{Prob}\{\mathrm{g}(\mathrm{R}, \mathrm{dr} ; \mathrm{y}) \leq \mathrm{x}\}=$ $\iint 1(g(R, d r ; y) \leq x\} \quad d F_{c t}(d r) d G_{e t}(R)$, where $G_{e t}$ is the empirical distribution of period $t$ (level) rents. (I thus ignore any dependence of $\mathrm{dr}$ on $\mathrm{R}$ ). Then the distribution of growth rates that would be observed according to the prevalence of grid pricing, given the counterfactual, is $F_{\text {gpt }}(x) \equiv \sum B(y ; t) F_{\text {gpt, } y}(x)$, where $B(y ; t)$ is the adjusted probability of each grid point, as described in footnote 12, and illustrated in Columns (3)-(4) of Table 9.

Figures $4 \mathrm{a}$ and $4 \mathrm{~b}$ add $\mathrm{F}_{\text {gp1975 }}$ and $\mathrm{F}_{\text {gp } 1981}$ (in bold) to Figures $3 \mathrm{a}$ and 3b, respectively. The $1980-81$ results are appealing. Above zero, and below the median, $F_{\text {gp1981 }}$ comes quite close to reproducing the empirical distribution. This is to be expected if grid pricing is the only mechanism by which otherwise positive rent growth is censored to zero. Below zero, $F_{\text {gp } 1981}$ falls below the counterfactual distribution for values greater than -.05, and thereafter falls on the counterfactual. The 1974-75 results are less attractive, because grid pricing indicates more censoring of otherwise positive rent growth than is inferred from a comparison of the counterfactual and empirical distributions. One suspects that the relative low rates of rent increase is responsible for that, that 
is, censoring occurs above the median.

The predicted nominal rigidity from grid pricing alone is then $F_{\text {gpt }}(0+)-F_{\text {gpt }}(0-)$, which is shown in Column (5) of Table 11. Column (6) subtracts Column (5) from Column (2); this is the incidence of nominal rigidity, net of the predicted amount from grid pricing. We see that, overall, of the 29 percent incidence, only 11 percent can not be explained by grid pricing. This is somewhat higher than the lower bound of nine percent obtained from subtracting twice $X^{\mathrm{P}}$ from Column (2).

If one conditions on turnover status, an interesting pattern emerges. Panels (b) and (c) of Table 11 restrict the sample to units that turned over in the previous period. Panel (b)'s sample is further restricted to units which did not turn over in the current period, while panel (c) includes the units that did turn over. Net of predicted rigidity due to grid pricing, the incidence of nominal rigidity is 21 percent of the continuing units, while only 3 percent among the turn over units. In other words, grid pricing can explain somewhat less than half of the nominal rigidity observed among turnover, while it can explain almost all of it among continuing units.

\section{Multivariate Analysis}

The single variate analysis thus far begs the question of whether any of these relationships are spurious. Because the 
sample size is not large enough to form cells of an adequate number of observations in all cases, I consider the ad hoc expedient of a probit analysis of nominal rigidity.

Estimates from the probit regressions are presented in Table 12. The dependent variable takes the value 1 if the nominal growth in rent is zero. All the regressors are dummy variables, with the dummy variables for a $\$ 1$ grid point, a 50 or more unit building, 1980-1 and a turnover unit serving as the omitted dummies, depending on the set of dummies included in each regression. Each of these values correspond to the cell with the lowest nominal rigidity, as indicated in the previous tables. Jointly, they define a baseline case, whose probability of nominal rigidity is given by the row labeled $M$ (constant).

The first three columns use the whole sample. Column (1) considers only the effect of the modulus t-1 rent. Column (2) adds dummy variables for the building size. We see that both sets of variables effect nominal rigidity. Column (3) adds year dummies.

The remaining columns restrict the sample to units that turned over in the previous year. Columns (4)-(6) repeat the earlier analysis for the restricted sample. Column (7) adds a dummy variable for units that did not turn over. The constant term in that Column indicates that (i) in 1981 (when median rents were increasing at 7 percent), a unit (ii) in a 50 plus unit building (iii) which turned over that year, and (iv) for which the previous year's price was set on a grid no coarser than one dollar, had only 
a two percent probability of having an unchanged nominal rent. Given that none of these variables should be correlated with within lease interviewing, we can once more conclude that observed nominal rigidity is not an artifact of within term interviewing, along the lines of the second point in section 2 .

If the unit was detached, instead, the probability of nominal rigidity would increase to 12 percent; if it did not turn over, the probability would be six percent more than the baseline case. A unit that was both detached and did not turn over, would have an incidence of nominal rigidity of 28 percent. If, in addition, the previous year's price was set on a \$100 grid, the probability would double to 56 percent. Thus, we see that the previous findings are not the results of spurious correlations. Each factor effects nominal rigidity in the same way that was demonstrated earlier, even when controlling for the others.

Finally, we can use the probit estimates to predict the degree of nominal rigidity we would observe in the absence of grid pricing. This approach has the advantage over constructing a counterfactual distribution with grid pricing, in that it places grid pricing and any remaining determinants of nominal rigidity on an equal footing. In Table 11, in contrast, nominal rigidity that would have arisen both because of grid pricing and because the unit was in a small building, say, is allocated to grid pricing.

To get the predicted incidence of nominal rigidity, net of grid pricing, I sum over the predicted probabilities obtained when 
the grid point dummies in Table 12 are all set equal to zero, and all other variables set to their actual values. The mean predicted incidence is presented in the last rows of the table. As expected, these are somewhat higher than the values shown in Column (6) of Table 11. Over all years, we see that the predicted net incidence is 16 percent in the whole sample (compared to 11 percent from Table 11). On the sub-sample of units that turned over in the previous period, it is 20 percent among the continuing units and, and 7 percent among those that turned over, (compared to 19 percent and 3 percent from Table 11).

\section{Other Margins}

The rent is not the only means by which the overall terms of trade between tenant and landlord might be altered. They are also determined by the assignment of responsibility for payment of utilities. As an instrument for splitting the surplus between landlord and tenant, this is a poor substitute for the rent, of course. Not only is it coarser than a change in the rent itself can be, but efficiency considerations will dictate their own assignment. In an efficient contract, which party pays the heating bill will depend on the monitoring cost, the price of the fuel and the elasticity of the demand for heating. The rent is the natural instrument to distribute the surplus. Nonetheless, there are two grounds on which to investigate whether these provisions are used 
as well. First, were nominal rigidity in the rent accompanied by offsetting changes to other terms of the contract between the landlord and the tenant, its macroeconomic consequences might be altered. Second, it would be useful to know if such inefficiencies arise out of nominal rigidity. Where there is nominal illusion, there may be inefficient contracts as well. Nominal illusion might lead to inefficiency in this way. ${ }^{14}$

Table 13 (14) shows the proportion of units in which the tenant pays the electricity (gas) bill according to whether the nominal rent changes or not, and according to which party bore the responsibility in the previous year. The rows titled "All Units" show that there is little year to year change in the assignment of responsibility for paying the fuel bills. The greater likelihood of a transition from the landlord paying the utility bill to the tenant than vice versa can be explained by the increase in fuel prices during this period, as well as the fact that installing monitoring equipment is a sunk investment.

When the tenant was previously responsible for the electricity bill, the total real housing cost to the renter can be reduced by more than the inflation rate when keeping the nominal rent

\footnotetext{
${ }^{14}$ The quality-adjusted price can also be changed by altering the level of maintenance. Likewise, as long as the quality of the unit is not a perfect substitute for "other goods" (money), there will be an efficient level of maintenance. I consider changes in the assignment of responsibility to pay utilities but not changes in quality, because the former is an objective, whereas the latter, as reported by the tenant, will be very subjective.
} 
unchanged by levying the electricity bill on the landlord instead. But the left panel of Table 13 shows that reallocation occurring in a mere half a percent of the cases in which the nominal rent is unchanged; furthermore, that is fewer than the proportion of cases when the nominal rent does change, which is one and a half percent. Likewise, when the electricity bill was previously paid by the landlord, the total real housing cost to the renter can be reduced by less than the inflation rate, or even increased, when keeping the nominal rent unchanged by levying the electricity bill on the tenant instead. That is done in only six percent of the relevant cases; again, this is less often than when there is a nominal change.

In this discussion, I have described Table 13 only, but the reader can see that the assignment of responsibility to pay gas bills follows the same basic patterns. These results clearly indicate that changes in the assignment of responsibility to pay the utility bills do not compensate for nominal rigidity, and, if anything, are complementary to it.

\section{Conclusion}

This paper has shown that there is substantial nominal rigidity in apartment rents, and that it varies in definite patterns. This finding gives credence to macroeconomic models that rely on such rigidities to explain aggregate economic fluctuations. 
About half of the incidence can be attributed to grid pricing. It is an open question whether the macroeconomic consequences of nominal rigidity are dependent on grid pricing or not.

Although I have motivated this paper by the macro literature on price stickiness, there are obvious microeconomic issues as well. Even if grid pricing does not lead to price rigidity at the macro level, it is still interesting at the micro level as a manifestation of "irrationality". Also at the micro level, the difference between the incidence levels among new and continuing tenants suggests that the old nominal price is a focal point in bargaining. This implies that nominal values have distributive consequences. They will have allocative consequences as well, when bargaining is not efficient. 


\section{References}

Akerlof, George, William Dickens and George Perry, "The Macroeconomics of Low Inflation," Brookings Papers on Economic Activity, 1996, 1 1-76.

Baar, Kenneth 1983. "Guidelines for drafting rent control laws: Lessons of a decade" Rutgers Law Review, 35(4):721-885.

Ball, Lawrence and N. Gregory Mankiw, "A Sticky-Price Manifesto", Carnegie Rochester Conference Series on Public Policy, Vol. 41 (1994), 127-151.

Block, W. and E. Olsen, Rent Control: Myths and Realities, The Fraser Institute, Vancouver 1981.

Caballero, R. J. and E. Engel, "Dynamic (S-s) Economies", Econometrica, 59 (1991), 1659-86.

Capek, Stella M. and John I. Gilderbloom. Community versus Commodity: Tenants and the American City, State University of New York Press, Albany 1992 .

Caplin, A. and D. Spulber, "Menu Costs and the Neutrality of Money", Quarterly Journal of Economics, 102 (1987) 703-725.

Caplin, A. and J. Leahy, "State Dependent Pricing and the Dynamics of Money and Output," Quarterly Journal of Economics, 106 (1991) 683-708.

Card, D. and D. Hyslop, "Does Inflation "Grease the Wheels of the Labor Market?"" in Christina D. Romer and David H. Romer, Reducing Inflation: Motivation and Strategy, 1996, 71-120.

Cecchetti, Stephen G. "The Frequency of Price Adjustment: A Study of the Newsstand Prices of Magazines," Journal of Econometrics 31 (1986) 255-274.

Downs, Anthony. Residential Rent Controls: An Evaluation, The Urban Land Institute, WAshington D.C., 1988.

Gilderbloom John et al. Rent Control: A Source Book, Foundation for National Progress, Housing Information Center, 1981.

Gilderbloom, John and Richard P. Appelbaum. Rethinking Rental 
Housing, Temple University Press, 1988.

Hubert, F. "Contracting with Costly Tenants", Regional Science and Urban Economics, 25 (1995) 631-654.

Kahn, S. "Evidence of Nominal Wage Stickiness from Microdata," American Economic Review, 1998.

Kashyap, "Sticky Prices: New Evidence from Retail Catalogs", Quarterly Journal of Economics, 110 (1995) 245-274.

Lach, S. and D. Tsiddon, "The Behavior of Prices and Inflation: An Empirical Analysis of Disaggregated Price Data", Journal of Political Economy, April 1992100 (2), 349-89.

Lach, S. and D. Tsiddon, "Staggering and Synchronization in PriceSetting: Evidence from Multiproduct Firms" American Economic Review, December 1996, 86 (5), 1175-1196.

Levy, Daniel, Mark Bergern, Shantanu Dutta, and Robert Venable. "The Magnitude of Menu Costs: Direct Evidence from Large U.S. Supermarket Chains", Quarterly Journal of Economics, August 1997, CX11 (3), 791-826.

Niebanck, Paul L., ed. The Rent Control Debate, The University of North Carolina Pres, Chapel Hill, 1985.

National Multi Housing Council the Spread of Rent Control 1981 and 1982, Washington, D.C.

Rydell, Peter C., C. Lance Barnett, Carol E. Hillestad, Michael P. Murray, Kevin Neels and Robert H. Sims, 1981. "The impact of rent control on the Los Angeles Housing Market" N-1747-LA (RAND).

Shesinski, E. and Y. Weiss, "Optimum Pricing Policy Under Stochastic Inflation," Review of Economic Studies, 50 (1983), 513529 .

Sweezy, Paul. "Demand Under Conditions of Oligopoly", Journal of Political Economy 47: 568-573. 
Table 1:

Distribution of Sample by SMSA

\begin{tabular}{|c|c|c|c|c|c|c|c|c|c|}
\hline \multirow[t]{2}{*}{ SMSA } & & Years & $74-75$ & $75-76$ & $76-77$ & $77-78$ & $78-79$ & $79-80$ & $80-81$ \\
\hline & $\mathrm{N}$ & \multicolumn{8}{|c|}{ Percent } \\
\hline Chicago & 3230 & 28.78 & 28.53 & 29.29 & 29.92 & 30.46 & 28.35 & 27.62 & 27.38 \\
\hline Columbus & 319 & 2.84 & 3.03 & 2.64 & 2.82 & 3.19 & 3.16 & 2.80 & 2.30 \\
\hline Dallas & 706 & 6.29 & 4.51 & 4.69 & 6.78 & 6.37 & 6.64 & 7.00 & 8.09 \\
\hline Detroit & 886 & 7.89 & 9.08 & 9.14 & 8.09 & 7.23 & 6.89 & 7.12 & 7.65 \\
\hline Hartford & 230 & 2.05 & 2.06 & 2.05 & 2.63 & 1.46 & 1.92 & 1.95 & 2.24 \\
\hline Kansas City & 505 & 4.50 & 4.06 & 4.39 & 4.64 & 4.38 & 4.59 & 4.93 & 4.48 \\
\hline Madison & 159 & 1.42 & 1.61 & 1.58 & 1.51 & 1.53 & 1.24 & 1.16 & 1.31 \\
\hline Memphis & 347 & 3.09 & 3.54 & 3.51 & 3.01 & 3.19 & 2.98 & 2.92 & 2.49 \\
\hline Milwaukee & 668 & 5.95 & 6.12 & 5.92 & 5.77 & 5.77 & 6.27 & 6.20 & 5.60 \\
\hline Minneapolis & 686 & 6.11 & 6.70 & 6.09 & 5.83 & 6.17 & 6.51 & 5.84 & 5.66 \\
\hline New Orleans & 443 & 3.95 & 3.41 & 4.10 & 4.14 & 4.45 & 4.09 & 3.77 & 3.67 \\
\hline Newport & 101 & 0.90 & 0.90 & 1.00 & 0.94 & 0.46 & 0.74 & 1.03 & 1.18 \\
\hline Orlando & 191 & 1.70 & 1.22 & 1.64 & 1.57 & 1.86 & 1.74 & 2.07 & 1.80 \\
\hline Phoenix & 484 & 4.31 & 3.48 & 3.16 & 3.83 & 4.31 & 5.02 & 5.41 & 4.98 \\
\hline Pittsburgh & 782 & 6.97 & 8.31 & 8.08 & 6.90 & 6.57 & 6.64 & 6.20 & 6.04 \\
\hline Portland & 584 & 5.20 & 4.70 & 4.51 & 4.58 & 5.44 & 5.71 & 5.72 & 5.79 \\
\hline Salt Lake City & 216 & 1.92 & 1.93 & 1.82 & 1.82 & 1.66 & 1.55 & 2.07 & 2.61 \\
\hline San Antonio & 267 & 2.38 & 2.70 & 2.11 & 2.26 & 2.59 & 2.23 & 2.37 & 2.43 \\
\hline Spokane & 129 & 1.15 & 1.16 & 1.35 & 0.75 & 1.0 & 1.24 & 1.22 & 1.31 \\
\hline Tacoma & 150 & 1.34 & 1.87 & 1.52 & 0.88 & 0.93 & 1.24 & 1.34 & 1.56 \\
\hline Wichita & 141 & 1.26 & 1.41 & 1.41 & 1.32 & 1.00 & 1.24 & 1.28 & 1.43 \\
\hline
\end{tabular}




\begin{tabular}{|c|c|c|c|c|c|c|c|}
\hline & \multicolumn{7}{|c|}{ Sign of Price Change } \\
\hline & Negative & Zero & Positive & Median & $\begin{array}{l}\text { Dispe } \\
\text { rsion }\end{array}$ & $\begin{array}{l}\text { Number } \\
\text { of Obs. }\end{array}$ & CPI Inflation \\
\hline $1974-5$ & 11.1 & 32.5 & 56.5 & .030 & .063 & 1553 & .091 \\
\hline $1975-6$ & 10.4 & 33.9 & 55.7 & .039 & .066 & 1707 & .058 \\
\hline $1976-7$ & 9.2 & 27.4 & 63.4 & .062 & .069 & 1594 & .065 \\
\hline $1977-8$ & 6.8 & 30.5 & 62.8 & .050 & .062 & 1507 & .076 \\
\hline $1978-9$ & 7.0 & 28.6 & 64.4 & .059 & .069 & 1612 & .113 \\
\hline $1979-80$ & 8.5 & 24.9 & 66.7 & .066 & .062 & 1644 & .135 \\
\hline $1980-81$ & 8.5 & 23.1 & 68.4 & .073 & .075 & 1607 & .103 \\
\hline $\begin{array}{l}\text { All } \\
\text { Years }\end{array}$ & 8.8 & 28.7 & 62.5 & .058 & .060 & 11224 & \\
\hline
\end{tabular}

The CPI inflation rate is calculated from the August CPI for all Urban Consumers (CPI-U). Dispersion is the difference between the 75th quartile and the median. 
Table 3

Nominal Rigidity and Median Rent

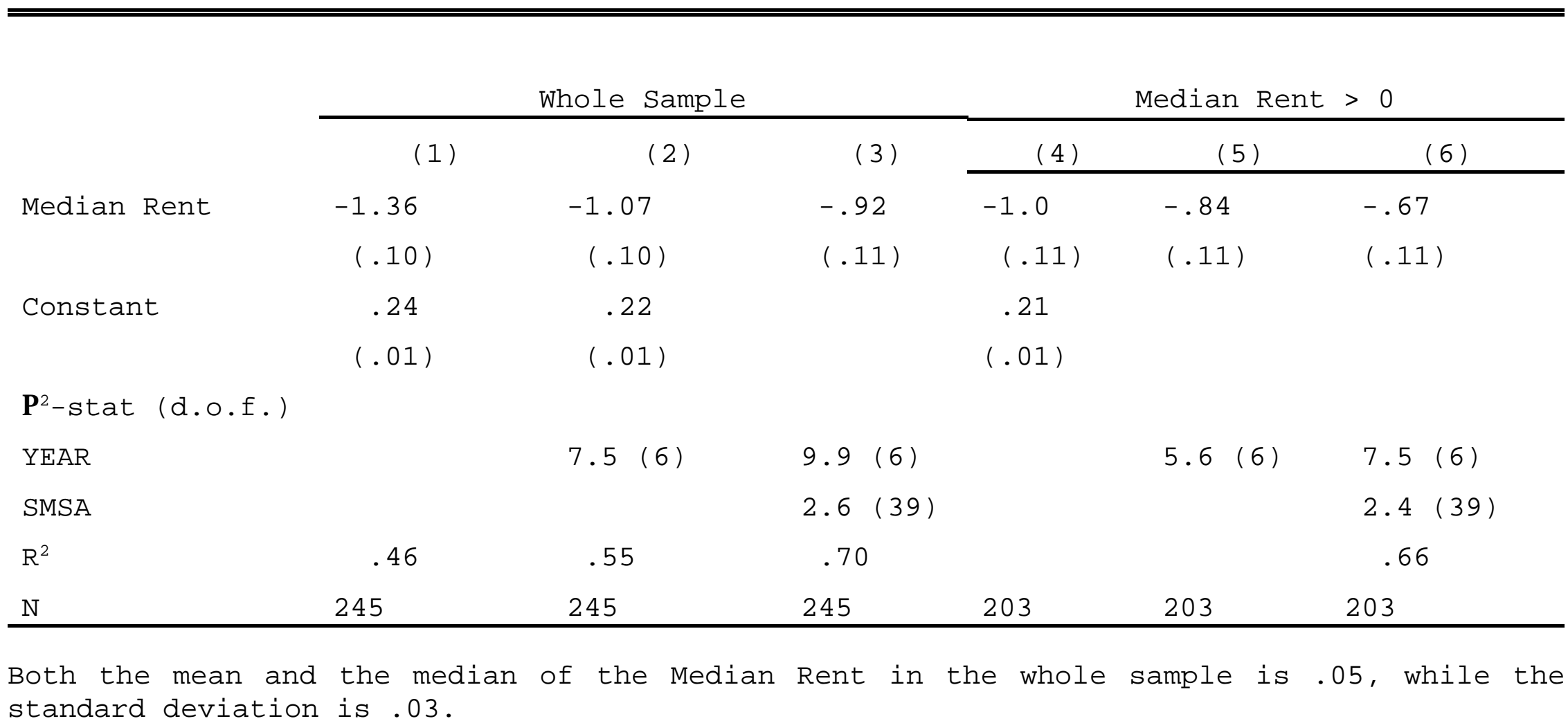


Table 4

Turnover Status

\begin{tabular}{rlc}
\hline \hline & $\begin{array}{l}\text { Percent that turn over in } \\
\text { year } t\end{array}$ & Number of Obs. \\
\hline All Units & 34.9 & \\
$\begin{array}{l}\text { Units that last turned over } \\
\text { in } . .\end{array}$ & & \\
$t-1$ & 49.4 & 1819 \\
$t-2$ & 36.3 & 921 \\
$t-3$ & 29.3 & 673 \\
$t-4$ or earlier & 15.9 & 2155 \\
\hline$t-1$ or earlier & 31.8 & 5568 \\
\hline
\end{tabular}


Table 5

Nominal Rigidity by Turnover Status and Year

\begin{tabular}{|c|c|c|c|c|c|c|c|c|c|c|}
\hline & & \multicolumn{3}{|c|}{ Whole Sample } & \multicolumn{3}{|c|}{$\begin{array}{c}\text { Unit Turned Over in } \\
\text { Previous Period }\end{array}$} & \multicolumn{3}{|c|}{$\begin{array}{l}\text { January - July } \\
\text { Subsample }\end{array}$} \\
\hline & & (1) & $(2)$ & (3) & $(4)$ & (5) & $(6)$ & $(7)$ & $(8)$ & $(9)$ \\
\hline & & Neg. & Zero & Pos. & Neg. & Zero & Pos. & Neg. & Zero & Pos \\
\hline \multirow[t]{3}{*}{$1974-5$} & $\mathrm{C}$ & 9 & 40 & 51 & 10 & 41 & 49 & 9 & 40 & 51 \\
\hline & $\mathrm{T}$ & 15 & 19 & 67 & 17 & 21 & 62 & 18 & 21 & 61 \\
\hline & $\mathrm{N}$ & 1553 & & & 579 & & & 883 & & \\
\hline \multirow[t]{3}{*}{$1975-6$} & $\mathrm{C}$ & 10 & 40 & 50 & 8 & 47 & 44 & 10 & 41 & 50 \\
\hline & $\mathrm{T}$ & 11 & 21 & 68 & 12 & 28 & 60 & 16 & 20 & 65 \\
\hline & $\mathrm{N}$ & 1707 & & & 622 & & & 837 & & \\
\hline \multirow[t]{3}{*}{$1976-7$} & $\mathrm{C}$ & 9 & 35 & 56 & 11 & 38 & 50 & 9 & 34 & 57 \\
\hline & $\mathrm{T}$ & 9 & 14 & 77 & 9 & 18 & 73 & 13 & 16 & 71 \\
\hline & $\mathrm{N}$ & 1594 & & & 605 & & & 880 & & \\
\hline \multirow[t]{3}{*}{$1977-8$} & $\mathrm{C}$ & 6 & 40 & 54 & 7 & 40 & 53 & 10 & 37 & 53 \\
\hline & $\mathrm{T}$ & 8 & 12 & 80 & 9 & 16 & 75 & 11 & 10 & 80 \\
\hline & $\mathrm{N}$ & 1507 & & & 616 & & & 833 & & \\
\hline \multirow[t]{3}{*}{$1978-9$} & $\mathrm{C}$ & 7 & 37 & 56 & 7 & 43 & 50 & 9 & 35 & 57 \\
\hline & $\mathrm{T}$ & 7 & 12 & 81 & 8 & 12 & 80 & 9 & 10 & 81 \\
\hline & $\mathrm{N}$ & 1612 & & & 612 & & & 870 & & \\
\hline \multirow[t]{3}{*}{$1979-80$} & $\mathrm{C}$ & 8 & 32 & 60 & 10 & 34 & 56 & 9 & 30 & 61 \\
\hline & $\mathrm{T}$ & 9 & 12 & 79 & 10 & 16 & 74 & 7 & 10 & 82 \\
\hline & $\mathrm{N}$ & 1644 & & & 655 & & & 1044 & & \\
\hline \multirow[t]{3}{*}{$1980-1$} & $\mathrm{C}$ & 8 & 30 & 61 & 7 & 35 & 58 & 8 & 33 & 59 \\
\hline & $\mathrm{T}$ & 9 & 10 & 81 & 10 & 13 & 77 & 8 & 10 & 81 \\
\hline & $\mathrm{N}$ & 1607 & & & 671 & & & 822 & & \\
\hline
\end{tabular}

The January - July sub-sample (columns (7)-(9)) is restricted to observations for which the previous year's tenant originally moved into the unit in the months of January through July. 


\section{Table 6}

Nominal Rigidity and the Number of Living Quarters

\begin{tabular}{lcccc}
\hline \hline $\begin{array}{c}\text { Number of Living } \\
\text { Quarters }\end{array}$ & $\begin{array}{l}\text { Percent for which } \\
\text { Rental }\end{array}$ & Growth Rate is: & $\begin{array}{l}\text { Number of } \\
\text { Observations }\end{array}$ \\
\hline \hline & Negative & Zero & Positive & \\
\hline $\begin{array}{l}\text { Mobile Home } \\
1-\text { Attached }\end{array}$ & 72 & 24 & 64 & 25 \\
& & 31 & 63 & 523 \\
$1-$ Detached & 9 & & & \\
2 & 10 & 46 & 45 & 1958 \\
$3-4$ & 10 & 41 & 49 & 1860 \\
$5-9$ & 7 & 20 & 73 & 1767 \\
$10-19$ & 8 & 18 & 75 & 1328 \\
$20-49$ & 9 & 14 & 77 & 1000 \\
50 and above & 9 & 13 & 78 & 920 \\
\hline
\end{tabular}


Table 7

Distribution of Length of Lease by Number of Living Quarters

\begin{tabular}{lccccc}
\hline \hline $\begin{array}{l}\text { Number of } \\
\text { Living } \\
\text { Quarters }\end{array}$ & No Lease & $\begin{array}{l}\text { Less than } \\
\text { Year }\end{array}$ & Year & $\begin{array}{l}\text { More } \\
\text { than } \\
\text { Year }\end{array}$ & N \\
\hline 1 & 14.6 & 39.3 & 43.5 & 2.6 & 944 \\
2 & 32.3 & 33.3 & 31.3 & 3.1 & 613 \\
$3-4$ & 24.0 & 40.0 & 35.3 & 0.7 & 413 \\
$5-9$ & 14.6 & 39.4 & 44.8 & 1.2 & 315 \\
$10-19$ & 8.3 & 40.0 & 48.0 & 3.7 & 254 \\
$20-49$ & 9.2 & 42.1 & 47.0 & 1.3 & 304 \\
50 and above & 1.4 & 42.9 & 55.3 & 1.9 & 1789 \\
\hline All Units & 14.6 & 39.3 & 43.5 & 2.3 & 4632 \\
\hline
\end{tabular}

Source: Property Owners and Managers Survey (POMS), 1993 microdata. 
Table 8

Interview Period of the Annual Housing Survey

\begin{tabular}{ll}
\hline \hline Year & Interview Period \\
\hline 1974 & August-October \\
1975 & October-December \\
1976 & October-December \\
1977 & October-January \\
1978 & October-January \\
1979 & September-December \\
1980 & mid August-December \\
1981 & September-December \\
\hline
\end{tabular}

Source: Annual Housing Survey, United States and Region Part A: General Housing Characteristics, U.S. Department of Commerce Series H-150, various years. 
Table 9

Grid Pricing

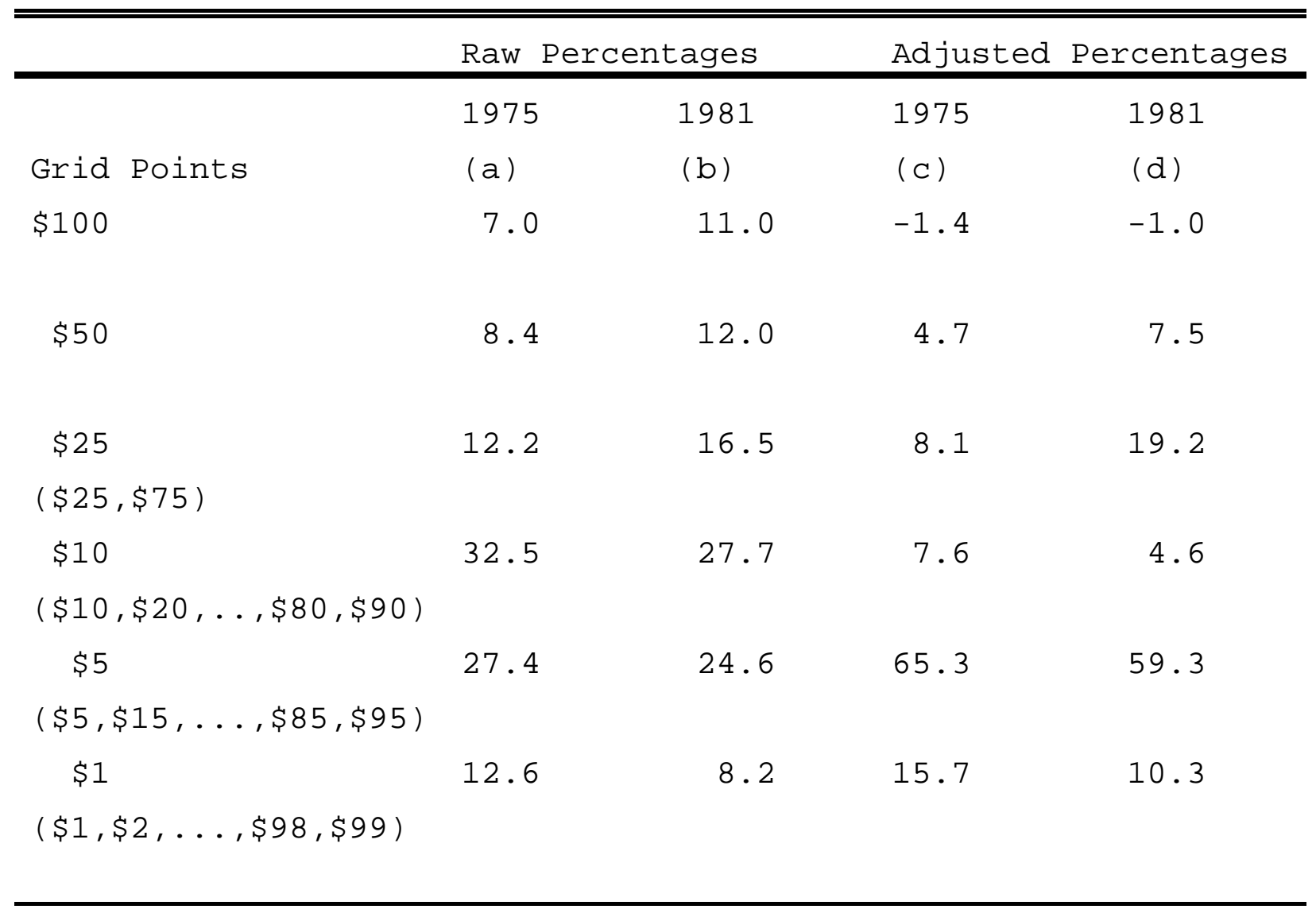


Table 10

Grid Pricing and Nominal Rigidity: 1975

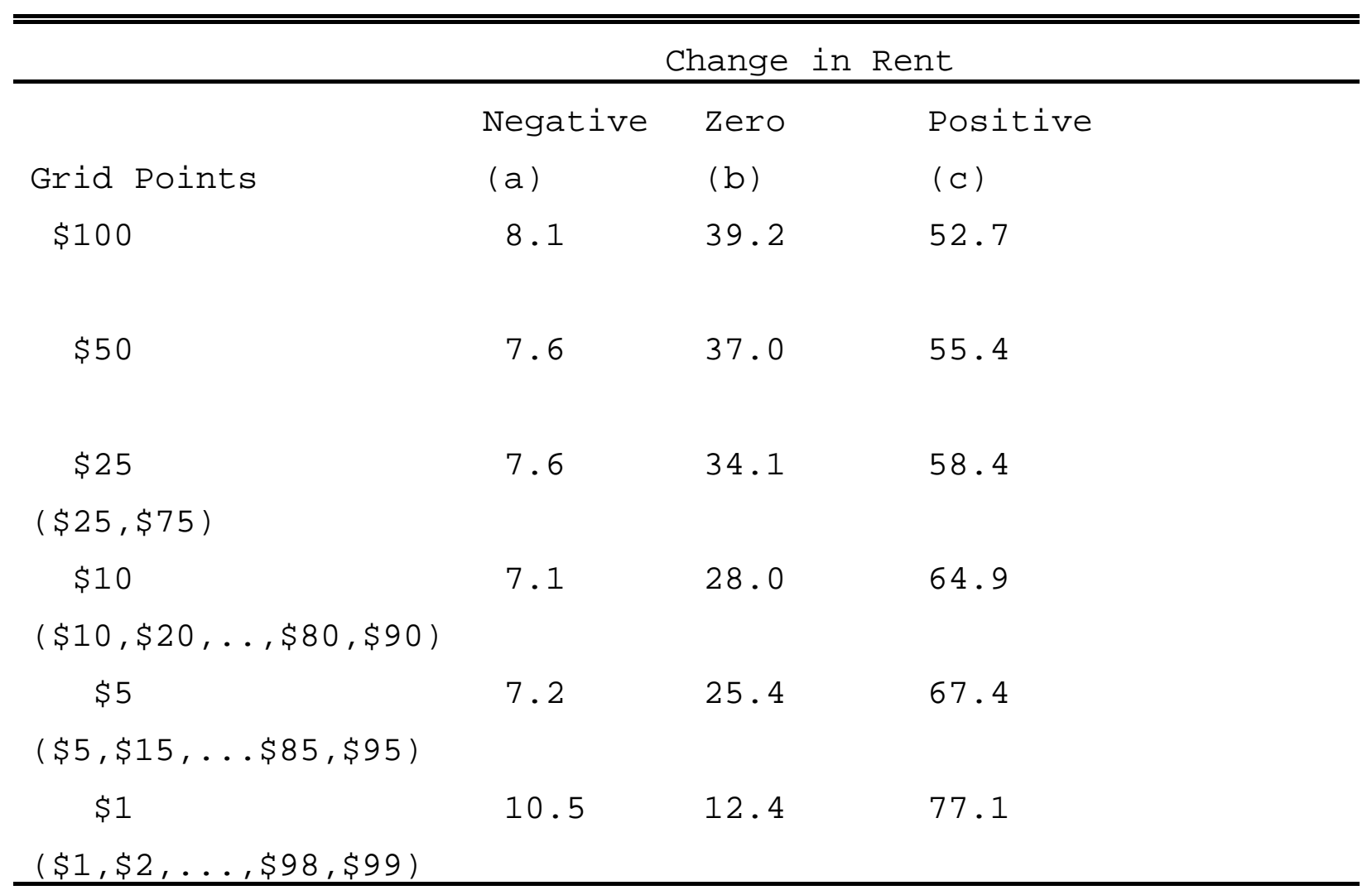


Table 12

\section{Probit Analysis of Nominal Rigidity}

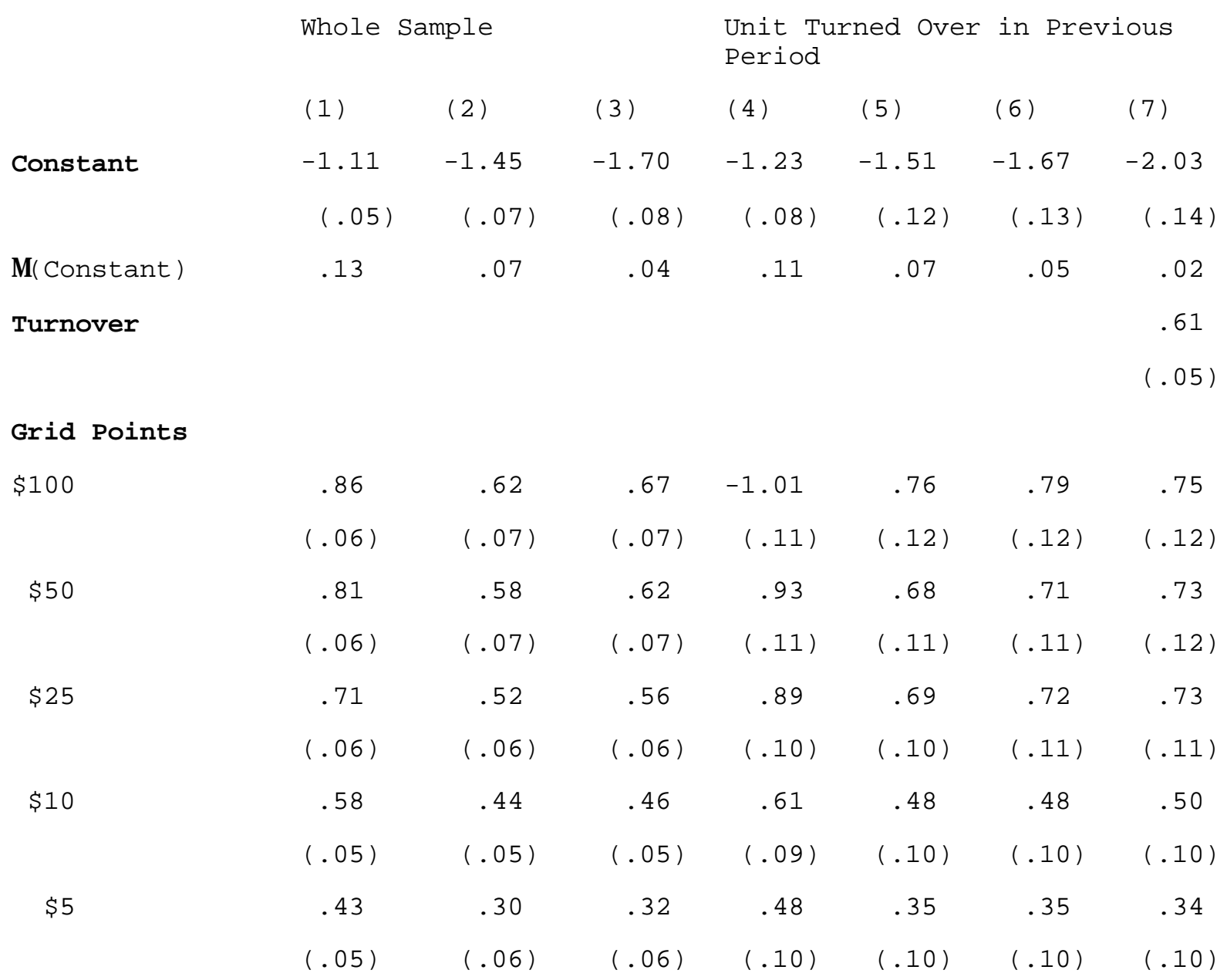

\section{Number of Living}

Quarters

Mobile Home

1 - Attached

1 - Detached

2

$3-4$

$\begin{array}{ll}.08 & .24 \\ (.43) & (.44) \\ .56 & .54 \\ (.08) & (.08) \\ .93 & .93 \\ (.07) & (.05) \\ .81 & .81 \\ (.07) & (.07) \\ .51 & .51 \\ (.07) & (.07)\end{array}$

$\begin{array}{lll}-.05 & .06 \quad .41\end{array}$

$\begin{array}{lll}(.57) \quad(.58) & (.58)\end{array}$

$.51 \quad .48 \quad .48$

$(.15) \quad(.11) \quad(.15)$

$\begin{array}{lll}.85 & .83 \quad .84\end{array}$

$(.11) \quad(.11) \quad(.11)$

$\begin{array}{lll}.84 & .81 \quad .80\end{array}$

$(.11) \quad(.11) \quad(.12)$

$\begin{array}{lll}.49 & .48 \quad .47\end{array}$

$(.11) \quad(.11) \quad(.11)$ 


$\begin{array}{cccccc}5-9 & .21 & .21 & .28 & .27 & .29 \\ 10-19 & (.07) & (.07) & (.11) & (.12) & (.11) \\ 20-49 & .15 & .18 & .13 & .13 & .17 \\ & (.07) & (.07) & (.11) & (.08) & (.12) \\ & -.02 & -.01 & .04 & .07 & .10 \\ & (.08) & (.08) & (.12) & (.09) & (.12)\end{array}$

\section{Years}

\begin{tabular}{|c|c|c|c|c|c|c|c|}
\hline \multirow[t]{2}{*}{$1974-5$} & \multicolumn{5}{|c|}{.24} & \multirow{2}{*}{$\begin{array}{c}.24 \\
(.08)\end{array}$} & \multirow{2}{*}{$\begin{array}{c}.28 \\
(.09)\end{array}$} \\
\hline & & & $(.08)$ & & & & \\
\hline \multirow[t]{2}{*}{$1975-6$} & & & .40 & & & .40 & .44 \\
\hline & & & $(.09)$ & & & $(.09)$ & $(.09)$ \\
\hline \multirow[t]{2}{*}{$1976-7$} & & & .15 & & & .15 & .19 \\
\hline & & & $(.09)$ & & & $(.09)$ & $(.09)$ \\
\hline \multirow[t]{2}{*}{$1977-8$} & & & .18 & & & .18 & .16 \\
\hline & & & $(.09)$ & & & $(.08)$ & $(.09)$ \\
\hline \multirow[t]{2}{*}{$1978-9$} & & & .11 & & & .11 & .11 \\
\hline & & & $(.09)$ & & & $(.09)$ & $(.09)$ \\
\hline \multirow[t]{2}{*}{$1979-80$} & & & .03 & & & .03 & .04 \\
\hline & & & $(.09)$ & & & $(.09)$ & $(.09)$ \\
\hline $\mathbf{P}^{2}$ & 278 & 877 & 966 & 140 & 324 & 354 & 521 \\
\hline$(d . \circ . f)$. & (5) & (13) & (19) & (5) & (13) & (19) & $(20)$ \\
\hline Log-Likelihood & -5827 & -5528 & -5483 & -2086 & -1994 & -1979 & -1896 \\
\hline Number of Obs. & 11,244 & 11,244 & 11,244 & 4,360 & 4,360 & 4,360 & 4,360 \\
\hline \multicolumn{8}{|l|}{$M(\bmod =\ldots 1)$} \\
\hline All Units & .13 & .17 & .16 & .10 & .13 & .13 & .14 \\
\hline Continuing & & & & .10 & .14 & .14 & .20 \\
\hline Turnover & & & & .10 & .12 & .12 & .07 \\
\hline
\end{tabular}


Table 13

Assignment of Responsibility for Payment of Electricity Charges Last Period Bill Paid by ...

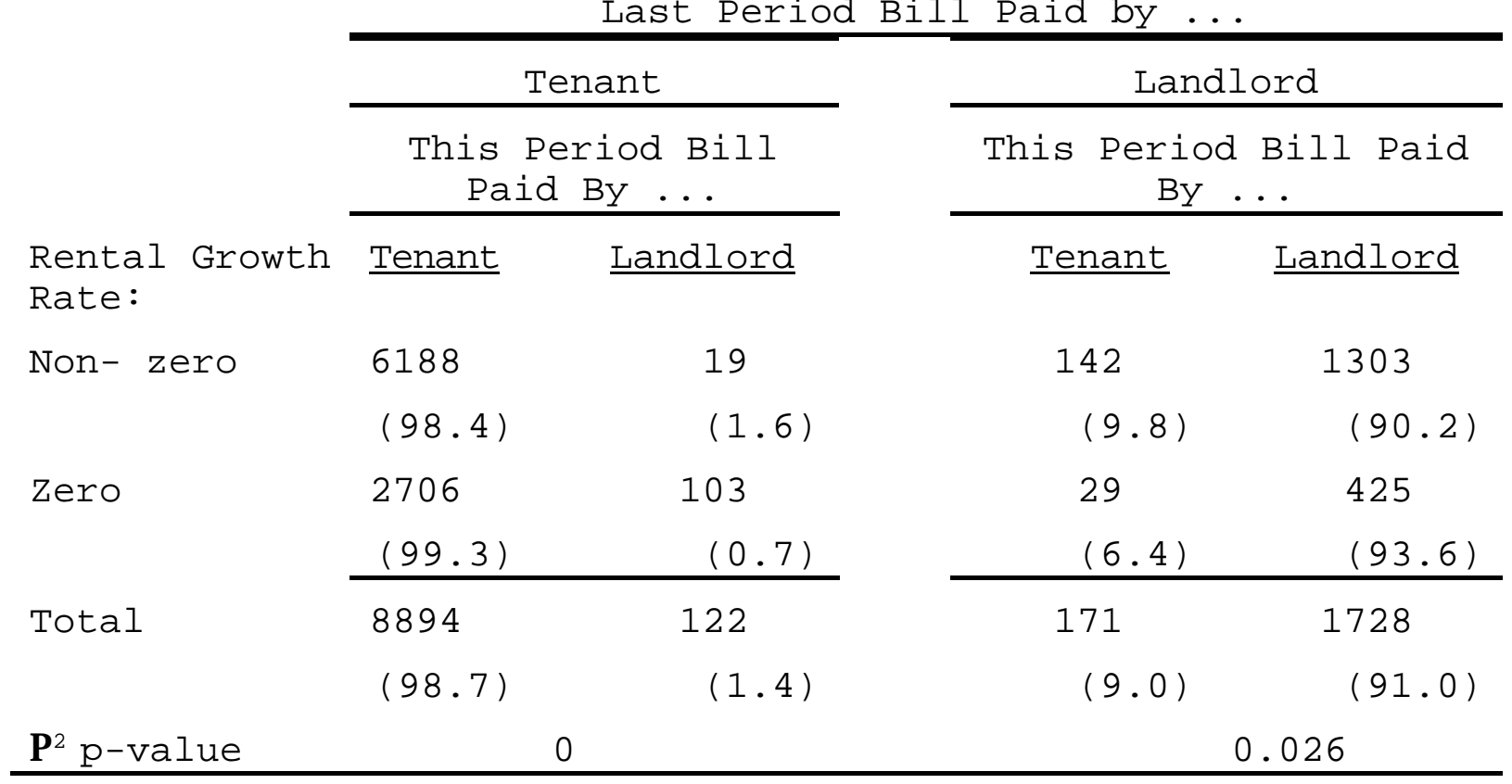

Table 14

Assignment of Responsibility for Payment of Gas Charges

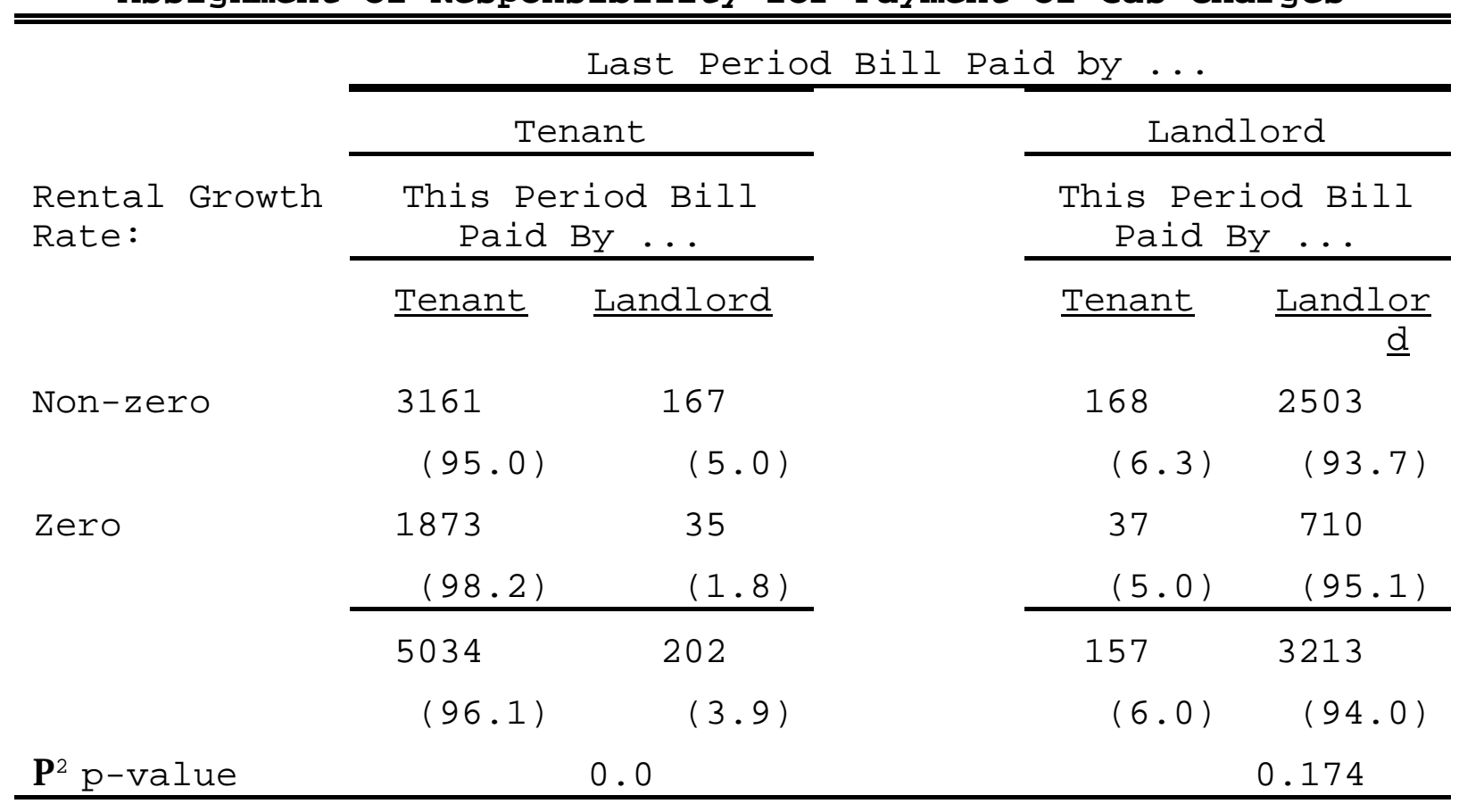



Table 11

Nominal Rigidity by Turnover Status and Year

\begin{tabular}{|c|c|c|c|c|c|c|}
\hline \multicolumn{7}{|c|}{ Whole Sample } \\
\hline & (1) & $(2)$ & (3) & (4) & (5) & $(6)$ \\
\hline & $\mathrm{F}_{\mathrm{C}}(0)$ & Observed & $X^{\mathrm{P}}$ & $X^{\mathrm{N}}$ & $\begin{array}{l}\text { Grid } \\
\text { Pricing }\end{array}$ & $\begin{array}{l}\text { Net } \\
\text { Incidence }\end{array}$ \\
\hline & $\mathrm{A}:$ & All Units & & & & \\
\hline $1974-5$ & 35 & 33 & 8 & 24 & 23 & 10 \\
\hline $1975-6$ & 36 & 34 & 8 & 26 & 22 & 12 \\
\hline $1976-7$ & 29 & 27 & 8 & 20 & 17 & 10 \\
\hline $1977-8$ & 26 & 31 & 12 & 19 & 18 & 13 \\
\hline $1978-9$ & 25 & 29 & 11 & 18 & 16 & 13 \\
\hline $1979-80$ & 22 & 25 & 12 & 13 & 15 & 10 \\
\hline $1980-1$ & 24 & 23 & 8 & 15 & 14 & 9 \\
\hline All Years & 32 & 29 & 10 & 19 & 18 & 11 \\
\hline
\end{tabular}

B: Continuing Units among Units that Turned Over in Previous Period

\begin{tabular}{|c|c|c|c|c|c|c|}
\hline $1974-5$ & - & 41 & - & - & & \\
\hline $1975-6$ & - & 47 & - & - & & \\
\hline $1976-7$ & 46 & 38 & 3 & 35 & 20 & 18 \\
\hline $1977-8$ & 43 & 40 & 4 & 36 & 20 & 20 \\
\hline $1978-9$ & 50 & 43 & 0 & 43 & 12 & 31 \\
\hline $1979-80$ & 30 & 34 & 14 & 20 & 21 & 13 \\
\hline $1980-1$ & 31 & 35 & 11 & 24 & 20 & 15 \\
\hline $1976-1981$ & 40 & 38 & 6 & 32 & 19 & 19 \\
\hline C: Turnover Units & among & $\begin{array}{c}\text { Units that } \\
\text { Periods }\end{array}$ & Turned & Over in & Previous & \\
\hline $1974-5$ & 30 & 21 & 8 & 13 & 23 & -2 \\
\hline $1975-6$ & 34 & 28 & 6 & 22 & 20 & 8 \\
\hline $1976-7$ & 24 & 18 & 3 & 15 & 13 & 5 \\
\hline $1977-8$ & 22 & 16 & 3 & 13 & 12 & 4 \\
\hline $1978-9$ & 20 & 12 & 0 & 12 & 11 & 1 \\
\hline $1979-80$ & 16 & 16 & 10 & 6 & 13 & 3 \\
\hline $1980-1$ & 20 & 13 & 3 & 10 & 13 & 0 \\
\hline All Years & 24 & 18 & 5 & 13 & 15 & 3 \\
\hline
\end{tabular}

Since the median growth rate in nominal rent for 1974-75 and 1975-76 was zero for continuing units, no counterfactual and so no allocation among otherwise positive or negative rents and no calculation of grid pricing incidence was possible. 


\begin{tabular}{|c|c|c|c|c|c|c|}
\hline & & \multicolumn{5}{|c|}{ Whole Sample } \\
\hline & & $(1)$ & (2) & (3) & $(4)$ & $(5)$ \\
\hline & & $\mathrm{Fe}(0)$ & Total & $N R-p$ & $\mathrm{NR}-\mathrm{n}$ & Grid \\
\hline & & & All Ur & ts & & \\
\hline \multirow[t]{3}{*}{$1974-5$} & All Units & 35 & 33 & 11 & 22 & 23 \\
\hline & Continuing & - & 41 & - & - & - \\
\hline & Turnover & 30 & 21 & 8 & 13 & 23 \\
\hline \multirow[t]{3}{*}{$1975-6$} & All Units & 36 & 34 & 10 & 26 & 22 \\
\hline & Continuing & - & 47 & - & - & - \\
\hline & Turnover & 34 & 28 & 12 & 22 & 20 \\
\hline \multirow[t]{3}{*}{$1976-7$} & All Units & 29 & 27 & 8 & 20 & 17 \\
\hline & Continuing & 46 & 38 & 3 & 35 & 20 \\
\hline & Turnover & 24 & 18 & 3 & 15 & 13 \\
\hline \multirow[t]{3}{*}{$1977-8$} & All Units & 26 & 31 & 11 & 19 & 18 \\
\hline & Continuing & 43 & 40 & 4 & 36 & 20 \\
\hline & Turnover & 22 & 16 & 3 & 13 & 12 \\
\hline \multirow[t]{3}{*}{$1978-9$} & All Units & 25 & 29 & 11 & 18 & 16 \\
\hline & Continuing & 50 & 43 & 0 & 43 & 12 \\
\hline & Turnover & 20 & 12 & 0 & 12 & 11 \\
\hline \multirow[t]{3}{*}{$1979-80$} & All Units & 22 & 25 & 11 & 13 & 15 \\
\hline & Continuing & 30 & 34 & 14 & 20 & 21 \\
\hline & Turnover & 16 & 16 & 10 & 6 & 13 \\
\hline \multirow[t]{3}{*}{$1980-1$} & All Units & 24 & 23 & 8 & 15 & 14 \\
\hline & Continuing & 31 & 35 & 11 & 24 & 20 \\
\hline & Turnover & 20 & 13 & 3 & 10 & 13 \\
\hline
\end{tabular}


Table $4 \mathrm{~b}$

Nominal Rigidity by Turnover Status and Year

\begin{tabular}{|c|c|c|c|c|c|c|c|c|c|}
\hline & \multicolumn{3}{|c|}{$1974-5$} & \multicolumn{3}{|c|}{$1975-6$} & \multicolumn{3}{|c|}{$1976-7$} \\
\hline & Neg. & Zero & Pos. & Neg. & Zero & Pos. & Neg. & Zero & Pos. \\
\hline $\mathrm{C}$ & 9 & 40 & 51 & 10 & 40 & 50 & 9 & 35 & 56 \\
\hline $\mathrm{T}$ & 15 & 19 & 67 & 11 & 21 & 68 & 9 & 14 & 77 \\
\hline \multirow[t]{2}{*}{$\mathrm{N}$} & 1553 & & & 1707 & & & 1594 & & \\
\hline & & $\begin{array}{l}197 \\
7-8\end{array}$ & & & $\begin{array}{l}197 \\
8-9\end{array}$ & & & $\begin{array}{l}197 \\
9-80\end{array}$ & \\
\hline $\mathrm{C}$ & 6 & 40 & 54 & 7 & 37 & 56 & 8 & 32 & 60 \\
\hline $\mathrm{T}$ & 8 & 12 & 80 & 7 & 12 & 81 & 9 & 12 & 79 \\
\hline \multirow[t]{2}{*}{$\mathrm{N}$} & 1507 & & & 1612 & & & 1644 & & \\
\hline & & $\begin{array}{l}198 \\
0-1\end{array}$ & & & & & & & \\
\hline $\mathrm{C}$ & 8 & 30 & 61 & & & & & & \\
\hline $\mathrm{T}$ & 9 & 10 & 81 & & & & & & \\
\hline $\mathrm{N}$ & 1607 & & & & & & & & \\
\hline
\end{tabular}


Table 4c

Nominal Rigidity by Turnover Status and Year:

Units that turned over in previous period

\begin{tabular}{|c|c|c|c|c|c|c|c|c|c|}
\hline & \multicolumn{3}{|c|}{$1974-5$} & \multicolumn{3}{|c|}{$1975-6$} & \multicolumn{3}{|c|}{$1976-7$} \\
\hline & Neg. & Zero & Pos. & Neg. & Zero & Pos. & Neg. & Zero & Pos. \\
\hline C & 10 & 41 & 49 & 8 & 47 & 44 & 11 & 38 & 50 \\
\hline $\mathrm{T}$ & 17 & 21 & 62 & 12 & 28 & 60 & 9 & 18 & 73 \\
\hline \multirow[t]{2}{*}{$\mathrm{N}$} & 579 & & & 622 & & & 605 & & \\
\hline & \multicolumn{3}{|c|}{$1977-8$} & \multicolumn{3}{|c|}{$1978-9$} & \multicolumn{3}{|c|}{$1979-80$} \\
\hline $\mathrm{C}$ & 7 & 40 & 53 & 7 & 43 & 50 & 10 & 34 & 56 \\
\hline $\mathrm{T}$ & 9 & 16 & 75 & 8 & 12 & 80 & 10 & 16 & 74 \\
\hline \multirow[t]{2}{*}{$\mathrm{N}$} & 616 & & & 612 & & & 655 & & \\
\hline & \multicolumn{3}{|c|}{$1980-1$} & & & & & & \\
\hline $\mathrm{C}$ & 7 & 35 & 58 & & & & & & \\
\hline $\mathrm{T}$ & 10 & 13 & 77 & & & & & & \\
\hline $\mathrm{N}$ & 671 & & & & & & & & \\
\hline
\end{tabular}


Table 8

Nominal Rigidity by Turnover Status:

January - July Sample

\begin{tabular}{|c|c|c|c|c|c|c|c|c|c|}
\hline & \multicolumn{3}{|c|}{$1974-5$} & \multicolumn{3}{|c|}{$1975-6$} & \multicolumn{3}{|c|}{$1976-7$} \\
\hline & Neg. & Zero & Pos. & Neg. & Zero & Pos. & Neg. & Zero & Pos. \\
\hline $\mathrm{C}$ & 9 & 40 & 51 & 10 & 41 & 50 & 9 & 34 & 57 \\
\hline $\mathrm{T}$ & 18 & 21 & 61 & 16 & 20 & 65 & 13 & 16 & 71 \\
\hline \multirow[t]{2}{*}{$\mathrm{N}$} & 883 & & & 837 & & & 880 & & \\
\hline & \multicolumn{3}{|c|}{$1977-8$} & \multicolumn{3}{|c|}{$1978-9$} & \multicolumn{3}{|c|}{$1979-80$} \\
\hline $\mathrm{C}$ & 10 & 37 & 53 & 9 & 35 & 57 & 9 & 30 & 61 \\
\hline $\mathrm{T}$ & 11 & 10 & 80 & 9 & 10 & 81 & 7 & 10 & 82 \\
\hline \multirow[t]{2}{*}{$\mathrm{N}$} & 833 & & & 870 & & & 1044 & & \\
\hline & & $1980-1$ & & & & & & & \\
\hline $\mathrm{C}$ & 7 & 35 & 58 & & & & & & \\
\hline $\mathrm{T}$ & 10 & 13 & 77 & & & & & & \\
\hline $\mathrm{N}$ & 671 & & & & & & & & \\
\hline
\end{tabular}

The sample is restricted to observations for which the previous year's tenant originally moved into the unit in the months of January through July. 


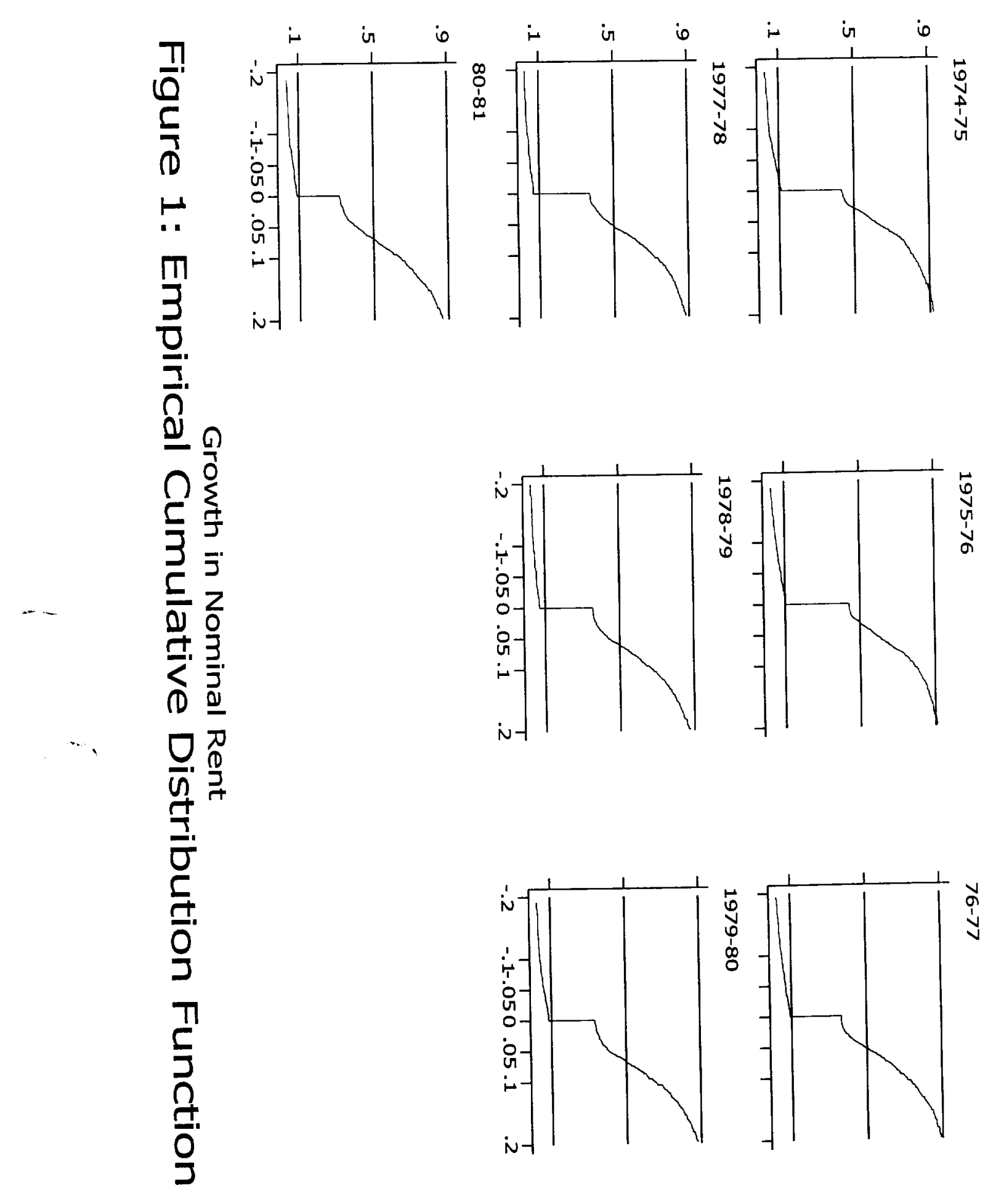




\section{Degree of Nominal Rigidity}

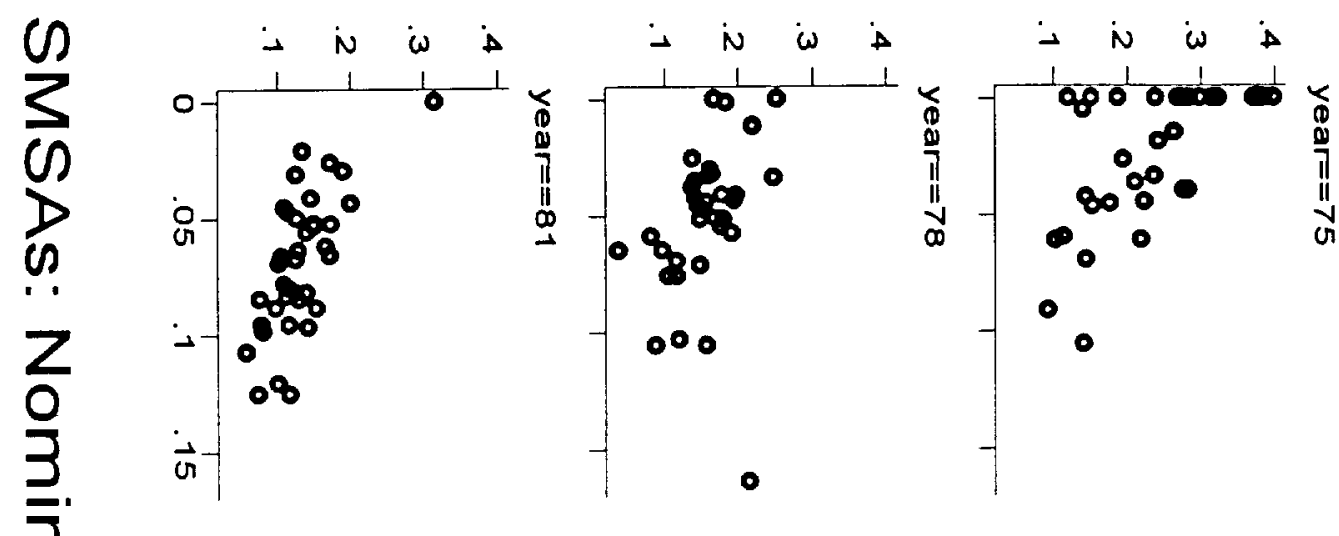

0

刃 $\frac{1}{0}$

궁

(s) 0

e 2

$\sum \xi$

0

밈

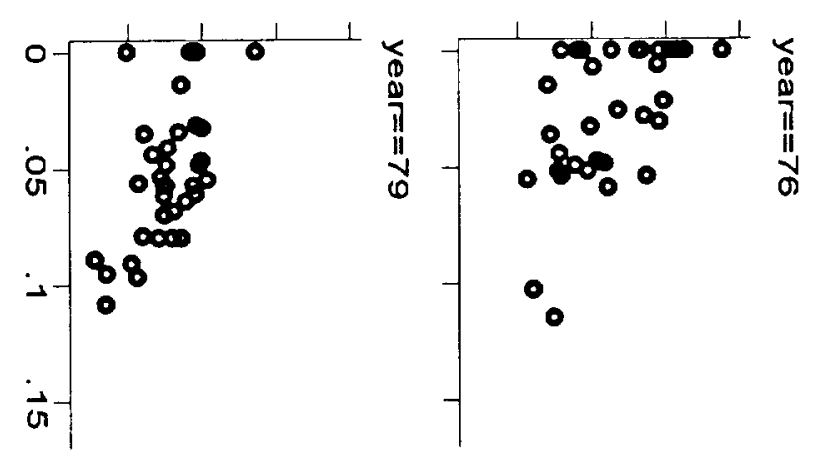

D

$\stackrel{D}{2}$

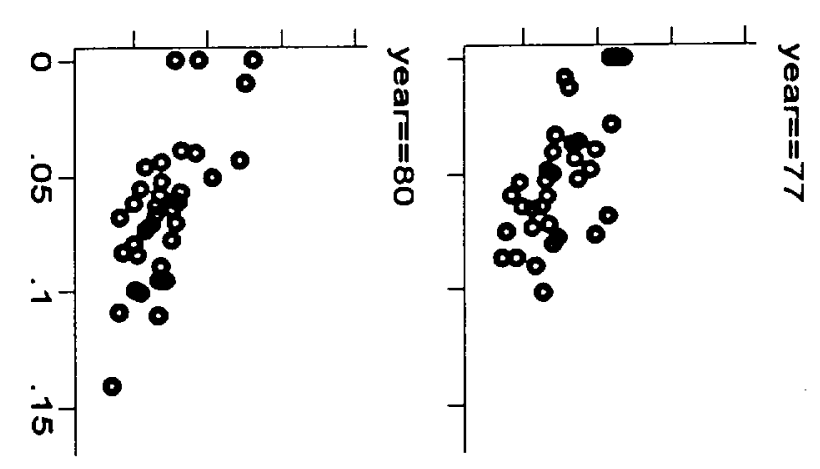




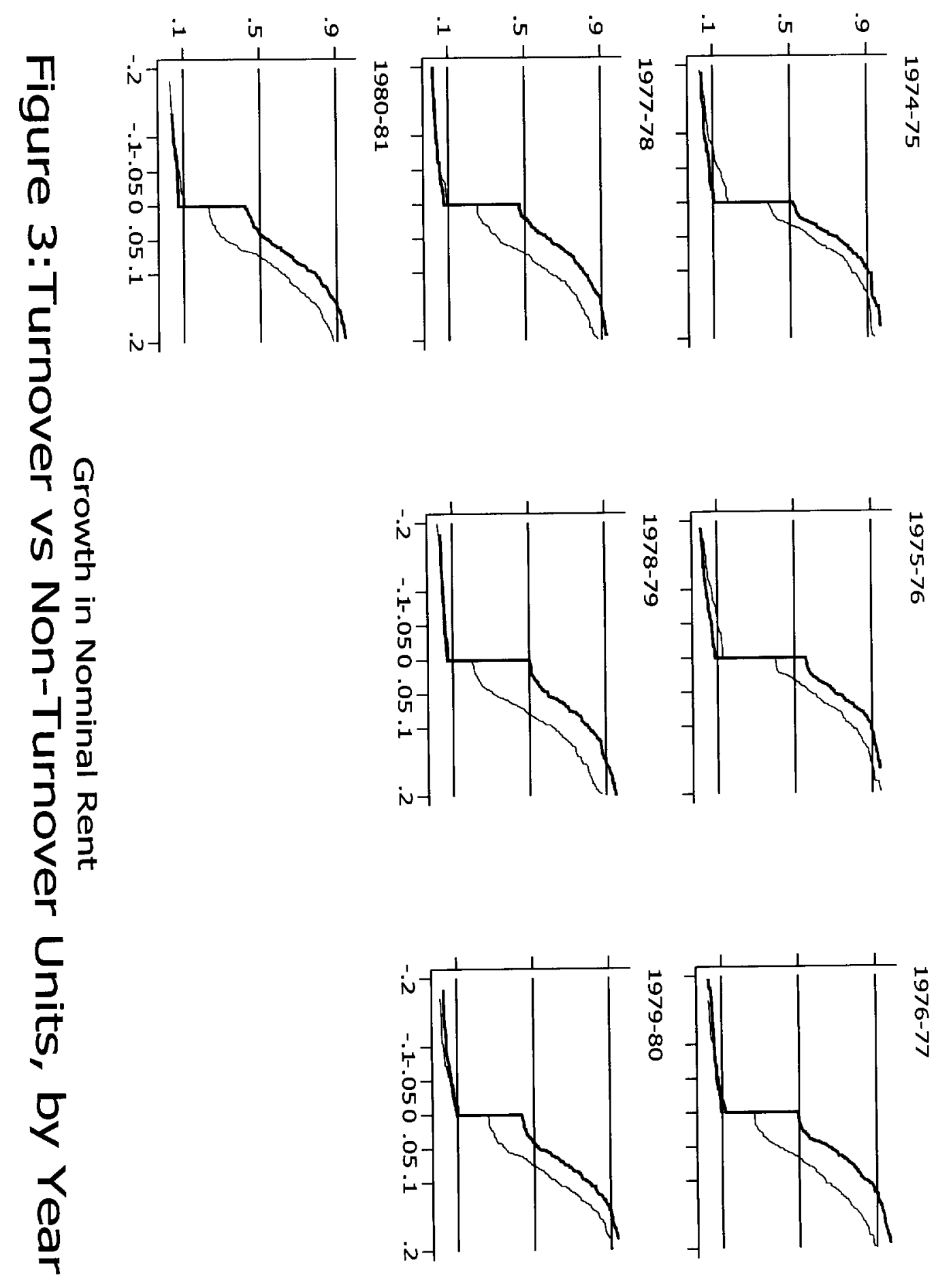




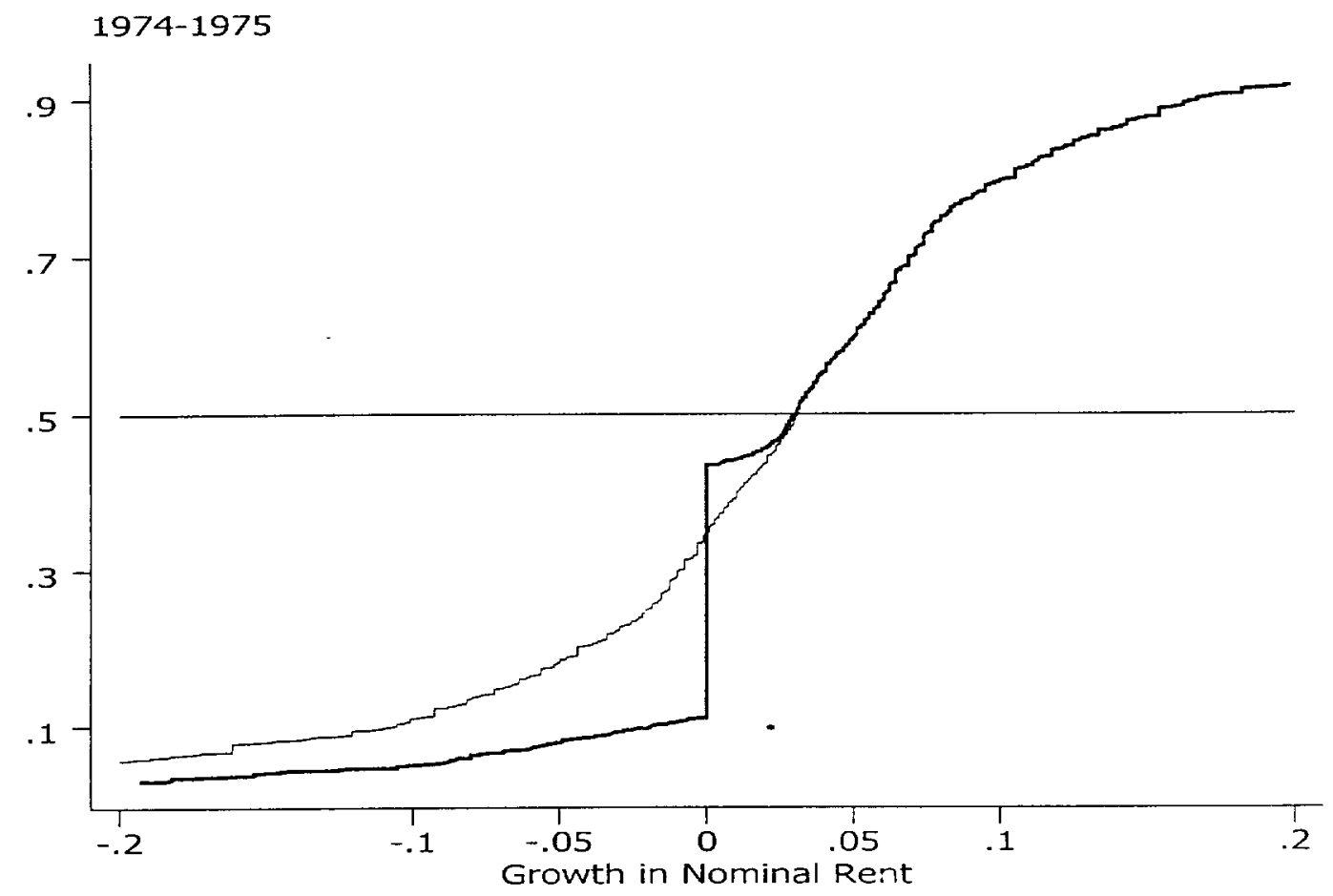

Figure 4a: Counterfactual vs Observed Distribution 


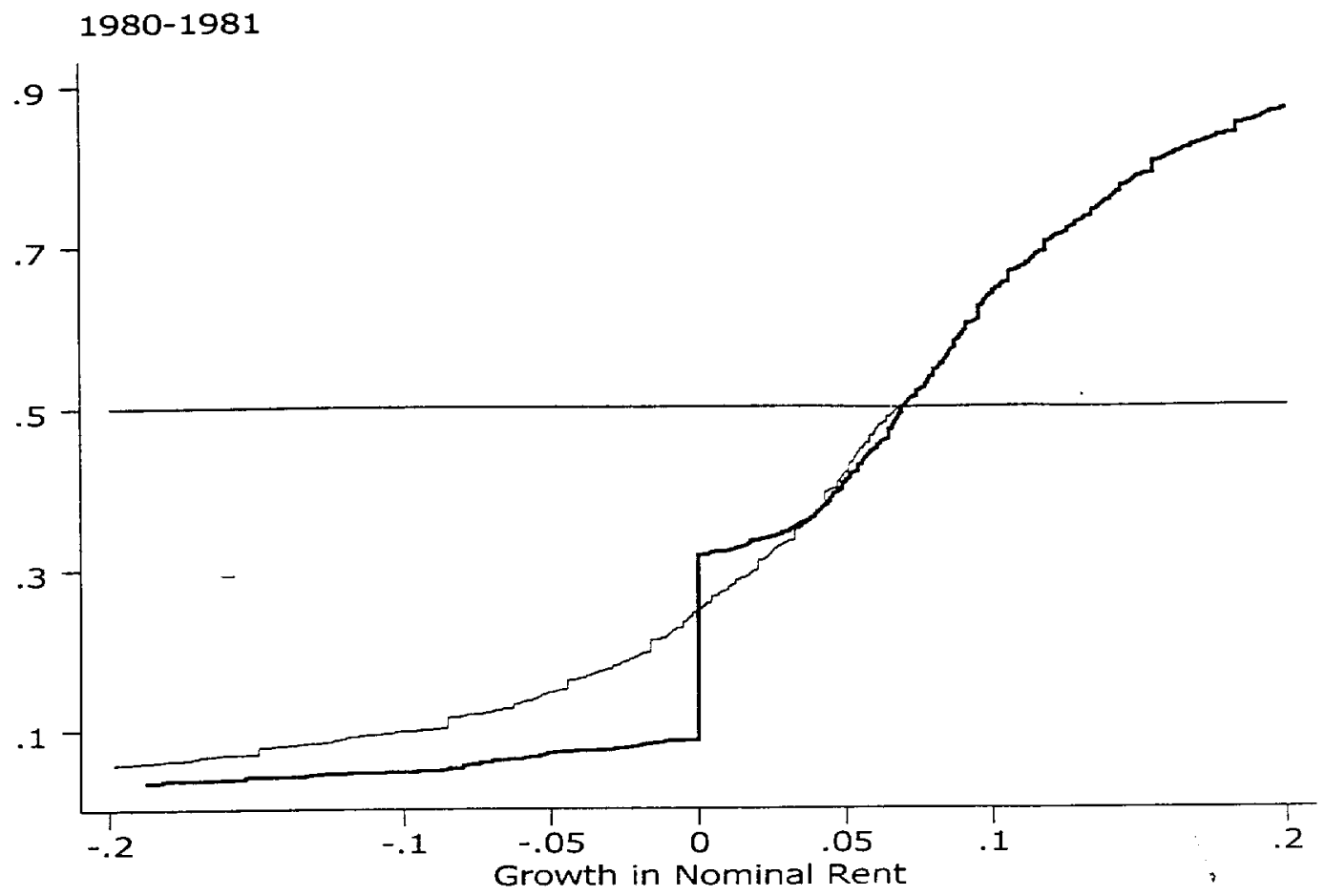

Figure 4b: Counterfactual vs Observed Distribution 


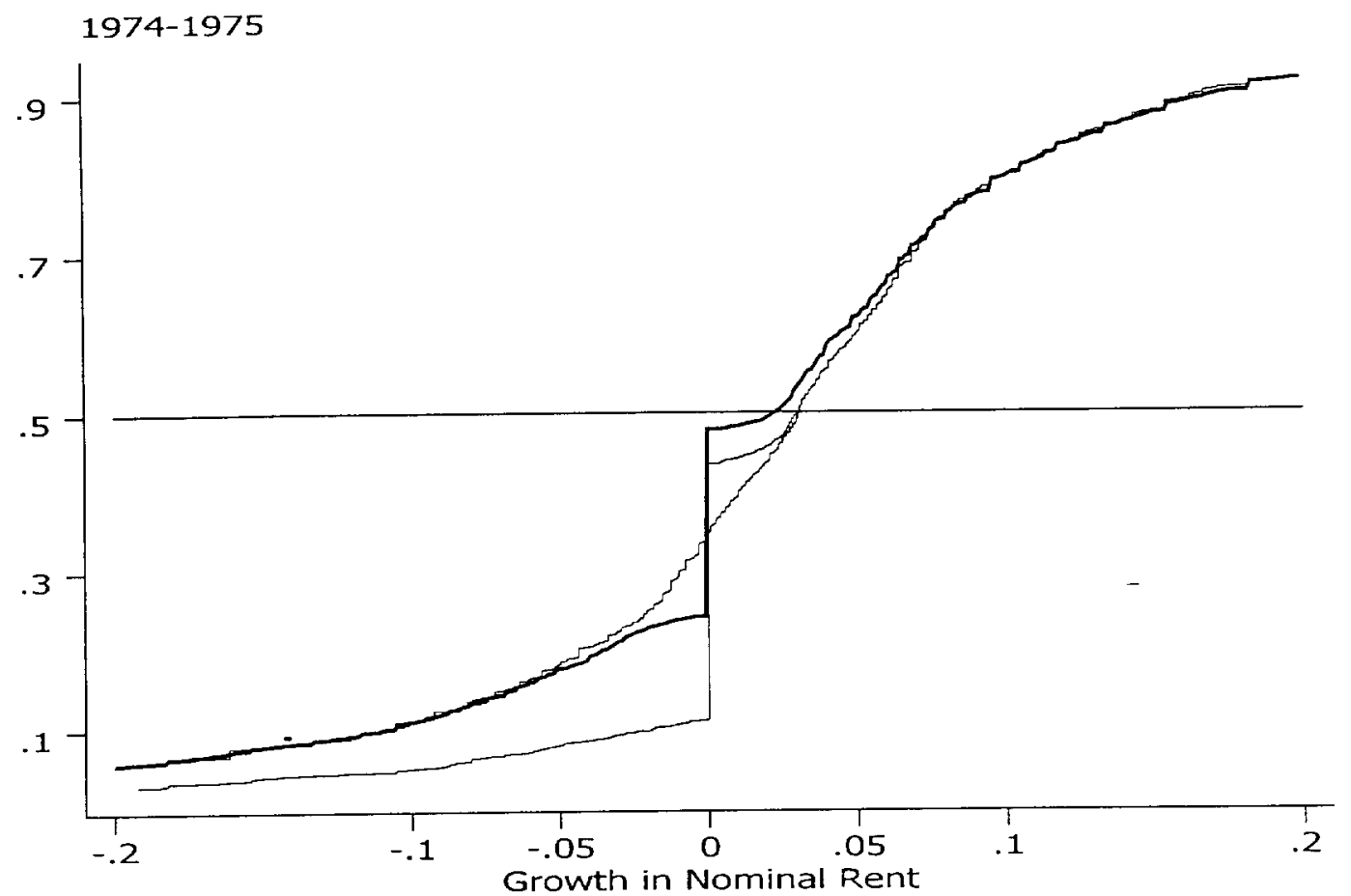

Figure 5a: Counterfactual with\&without Grid Pricing vs Observed 


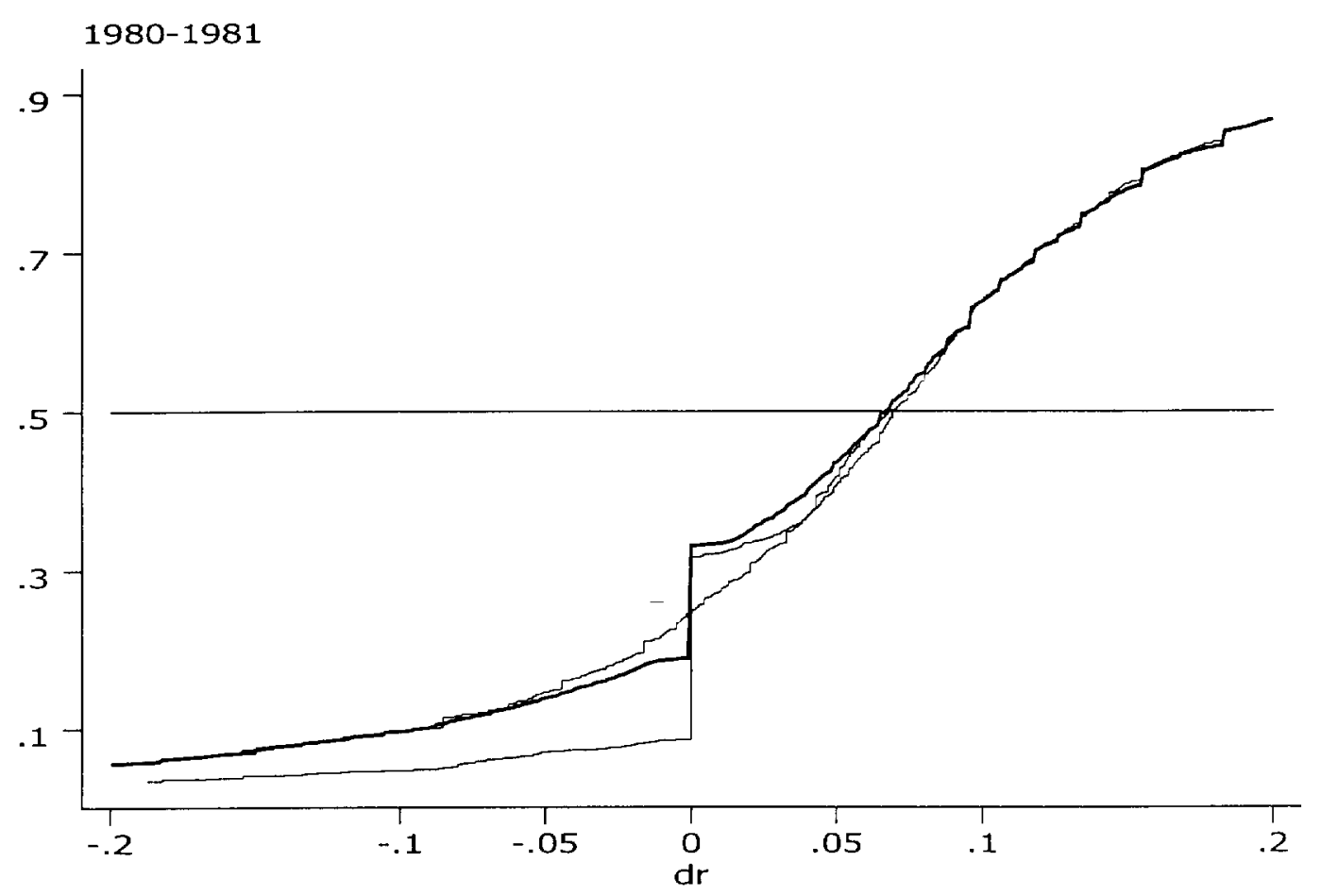

Figure 5b: Counterfactual with\&without Grid Pricing vs Observed 